\title{
MEMORANDUM
}

No 14/2014

\section{Resource Prices and Planning Horizons}

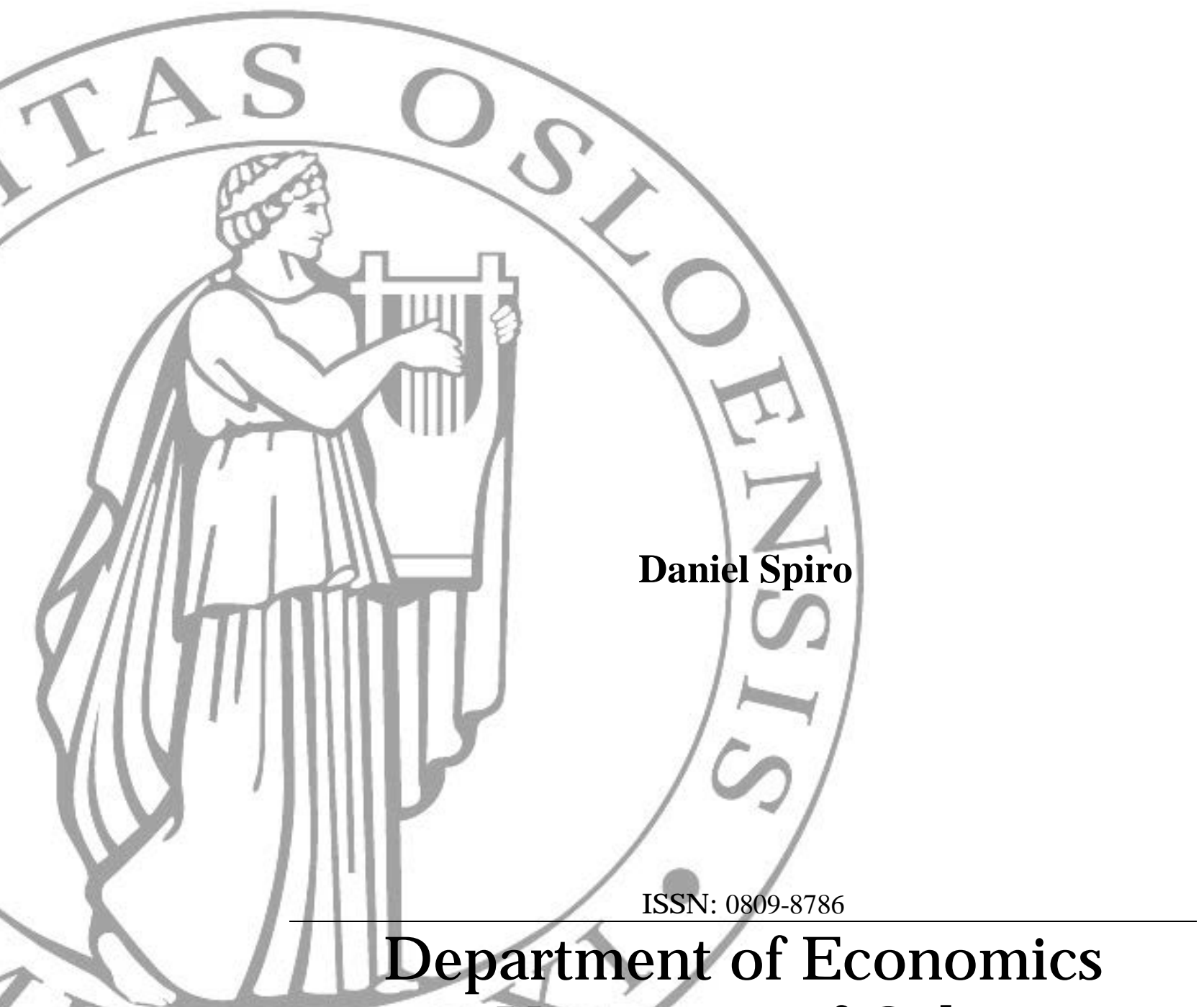

University of O slo 
This series is published by the

\section{University of Oslo Department of Economics}

P. O.Box 1095 Blindern

N-0317 OSLO Norway

Telephone: + 4722855127

Fax: $\quad+4722855035$

Internet: http://www.sv.uio.no/econ

e-mail: $\quad$ econdep@econ.uio.no
In co-operation with

The Frisch Centre for Economic

Research

Gaustadalleén 21

N-0371 OSLO Norway

Telephone: $\quad$ +4722958820

Fax: $\quad+4722958825$

Internet: $\quad$ http://www.frisch.uio.no

e-mail: $\quad$ frisch@frisch.uio.no

\section{Last 10 Memoranda}

\begin{tabular}{|c|c|}
\hline No $13 / 14$ & $\begin{array}{l}\text { Johan Gars and Daniel Spiro } \\
\text { Uninsurance through Trade }\end{array}$ \\
\hline No $12 / 14$ & $\begin{array}{l}\text { Moti Michaeli and Daniel Spiro } \\
\text { The Distribution of Individual Conformity under Social Pressure }\end{array}$ \\
\hline No $11 / 14$ & $\begin{array}{l}\text { Ingvild Almås, Åshild Auglænd Johnsen and Andreas Kotsadam } \\
\text { Powerty in China as Seen from Outer Space }\end{array}$ \\
\hline No $10 / 14$ & $\begin{array}{l}\text { Nico Keilman and Coen van Duin } \\
\text { Stochastic Household Forecast by Coherent Random Shares Prediction }\end{array}$ \\
\hline No $09 / 14$ & $\begin{array}{l}\text { Mads Greaker, Michael Hoel and Knut Einar Rosendahl } \\
\text { Does a Renewable Fuel Standard for Biofuels Reduce Climate Costs? }\end{array}$ \\
\hline No $08 / 14$ & $\begin{array}{l}\text { Karine Nyborg } \\
\text { Project Evaluation with Democratic Decision-making: What Does Cost- } \\
\text { benefit Analysis Really Measure? }\end{array}$ \\
\hline No $07 / 14$ & $\begin{array}{l}\text { Florian Diekert, Kristen Lund and Tore Schweder } \\
\text { From Open-Access to Individual Quotas: } \\
\text { Disentangling the Effects of Policy Reform and } \\
\text { Environmental Changes in the Norwegian Coastal Fishery }\end{array}$ \\
\hline No $06 / 14$ & $\begin{array}{l}\text { Edwin Leuven, Erik Plug and Marte Rønning } \\
\text { Education and Cancer Risk }\end{array}$ \\
\hline No $05 / 14$ & $\begin{array}{l}\text { Edwin Leuven, Erik Plug and Marte Rønning } \\
\text { The Relative Contribution of Genetic and Environmental Factors to Cancer } \\
\text { Risk and Cancer Mortality in Norway }\end{array}$ \\
\hline No $04 / 14$ & $\begin{array}{l}\text { Tone Ognedal } \\
\text { Morale in the Market }\end{array}$ \\
\hline
\end{tabular}

Previous issues of the memo-series are available in a PDF® format at: http://www.sv.uio.no/econ/english/research/memorandum/ 


\title{
Resource prices and planning horizons
}

\author{
Daniel Spiro*
}

Memo 14/2014-v1
(This version May 2014)

\begin{abstract}
This paper shows that a seemingly simple assumption, regarding the time horizon of economic agents, can reconcile the puzzling long run price dynamics of exhaustible resources such as oil, gas and metals. It does so by exploring the possibility that economic agents use a rolling planning horizon, meaning that they make a plan over a finite number of years but update this plan on a regular basis. This behavior can be observed in the business plans of firms, in US social security and in the extraction decisions of natural resource owners. While leaving other macroeconomic models intact, when used in models of natural resources rolling horizon planning alters the outcomes. It has the effect of removing the scarcity consideration of resource owners, thus letting only operating costs and demand determine the extraction rate. This implies that extraction will be non-decreasing and resource prices non-increasing for a long period of time and that there will be no connection between the price growth and the interest rate - in line with the trends of a majority of exhaustible resources in the last century. A calibration of the model to the oil market yields a price which closely fits the gradually falling real oil price after WWII and the sharply increasing price after 1998. It further suggests that, while long run scarcity was not an important parameter on the oil market in the 20th century, it has been important in shaping the oil price from around 1998 and onwards.
\end{abstract}

JEL classification: D80, Q31, Q41

Keywords: Resource extraction; Oil price; Rolling horizons; Decision-making under uncertainty.

${ }^{*}$ Department of Economics, University of Oslo, P.O box 1095, Blindern, 0317 OSLO, Norway, Tel: +47 22855137, daniel.spiro@econ.uio.no. 


\section{Introduction}

The long run price evolution of exhaustible resources such as oil, natural gas and metals and the functioning of these markets are central for a variety of public policy issues. These range from climate policy (e.g. Golosov et al., 2013; van der Ploeg \& Withagen, 2012), to issues of sustainability and intergenerational consumption smoothing (e.g. Hartwick, 1977; Smulders \& de Nooij, 2003) to national exploration investments and unilateral taxation (e.g. Liski \& Tahvonen, 2004). But what shapes the long run price trends of exhaustible resources? Three stylized facts are at the heart of this question:

1. The long run pattern of prices was falling or constant during the 20th century. This can be seen in the upper panel of Figure 1 which shows a composite price index of 57 resources. Apart from temporary spikes during the first world war and the oil crisis years of the 70:s, the price was secularly falling or constant up until the turn of the century.

2. During the 20th century there does not seem to have existed any substantial scarcity rents for resources. In particular, and in opposite to standard theory, the empirical literature does not support an increasing scarcity rent and a positive connection between price growth and the interest rate. ${ }^{1}$

3. The price of many resources, and in particular oil, started increasing sharply around the turn of the millennium (see the lower panel of Figure 1 for the oil price). This seems to have been accompanied by substantial and increasing rents for, in particular, oil and other energy resources (Hamilton, 2009). ${ }^{2}$

Put together, these three facts are puzzling and remain largely unexplained by theory to date. To see why, consider a basic exhaustible resource model (due to Hotelling, 1931). The logic of no-arbitrage in such a model suggests that, in a general equilibrium, resource owners need to be indifferent between either keeping the resource in the ground or extracting it and putting the money in the bank. This leads to the conclusion that the resource price (net of marginal extraction costs) should rise at the rate of interest or, at the very least, that there should be a positive correlation between price growth

\footnotetext{
${ }^{1}$ The theoretical prediction is explained below. Examples of empirical studies are Heal \& Barrow (1980), Abgeyebge (1989) and Hamilton (2009). It should be noted that the scarcity rent is not directly observable. To get around these issues some studies have used indirect measures of scarcity. For instance, Halvorsen \& Smith (1984, 1991), Chermak \& Patrick (2001) and Ellis \& Halvorsen (2002). For a further discussion of those empirical results see Hart \& Spiro (2011). In the forecasting literature it has been found that the interest rate does not add accuracy in predicting oil prices (Alquist, Kilian and Vigfusson, 2012).

${ }^{2}$ Historically there are several examples of temporary price (and profit) spikes for various resources. E.g., during the oil crisis in the 70:s. However, the explanations for those spikes (e.g. Barsky \& Kilian, 2002; Hamilton, 2003) do not seem suitable to explain the surge in oil and other resource prices and profits during the last 10-15 years. For instance, Hamilton (2009, p. 180) has expressed that with regard to oil "...the scarcity rent may have been negligible for previous generations but may now be becoming relevant".
} 

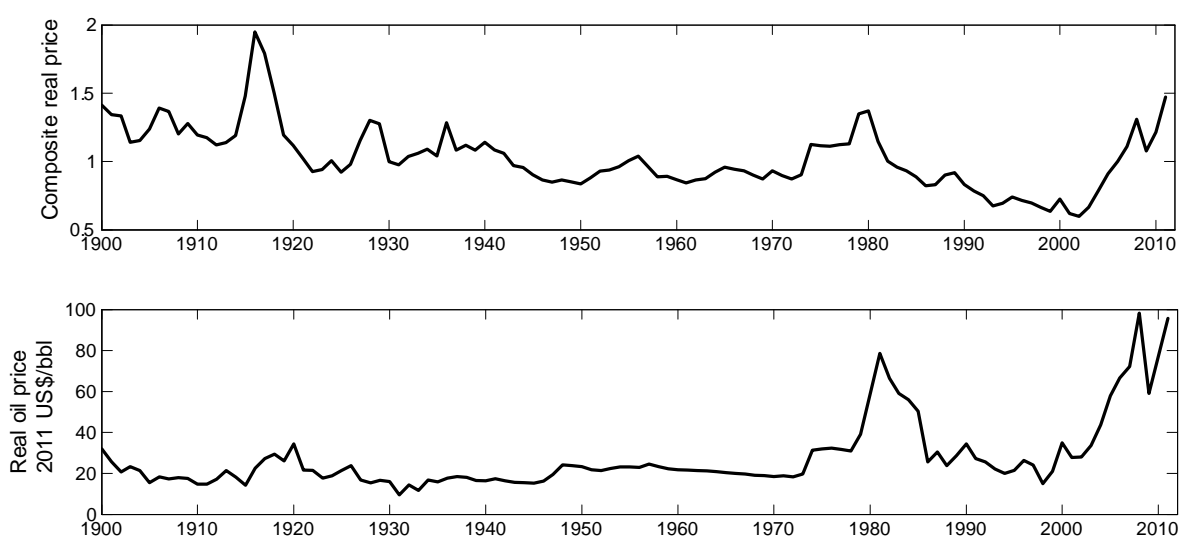

Figure 1: Upper panel: Real resource price composite. Consists of 57 mineral and energy commodities, weighted equally. Prices are normalized so that the average price for each commodity over the period equals one. Lower panel: Real oil price. Sources: www.usgs.gov, www.eia.gov.

and the interest rate. ${ }^{3}$ Such a model can therefore possibly explain facts one and three, if extraction cost parameters can be chosen freely, but naturally it cannot explain fact number two.

If we instead assume the resource is inexhaustible (i.e., that it is in infinite supply), then fact two can be explained (since there is no scarcity). However, to explain facts one and three one would need to show that extraction costs first fell secularly for a century and then increased suddenly at the turn of the century. This does not have empirical support (see Lin \& Wagner, 2007).

One supposed explanation for falling prices, which perhaps is mainly common in the public debate, is that the world keeps finding new deposits of various resources. However, as has been shown by Arrow \& Chang (1982), this explanation is a misconception. If agents are forward looking they will incorporate the possibility of new reserve findings and form beliefs over the total reserves, including those not yet discovered. The price may drop or jump temporarily as beliefs are updated. But with beliefs which are correct "on average" the price must rise over the long run for most resources as the current reserves and those expected to be discovered become more scarce as extraction is taking place. What is in particular problematic with this explanation is that, even if the market would be constantly surprised by new reserve findings, it will still imply a correlation of price growth and the interest rate in between the surprises which leaves fact two unresolved.

Another extension is to introduce a backstop technology which makes the resource worth little or nothing. Kamien \& Schwartz (1978) and Davison (1978) have shown that if the arrival date of the backstop is uncertain this will essentially only add a component of discounting (due to the additional risk to the owner) thus leaving the basic predictions of

\footnotetext{
${ }^{3}$ See Hotelling (1931) and Dasgupta \& Heal (1974) for the basic model and Weinstein \& Zeckhauser (1975) and Solow \& Wan (1976) for the addition of extraction costs.
} 
the Hotelling model intact. For a backstop model to alter the basic results, of increasing prices and a correlation with the interest rate, one needs to assume that the backstop arrives with certainty after a known date. For instance, economic agents today need to be entirely sure that cold fusion will arrive in no more than, say, 30 years. Such an assumption may be reasonable for some resources but not for others, such as fossil energy resources. Supposing that the assumption holds, the model then produces either a price which decreases throughout, increases throughout, or first increases and then decreases (see for example Heal, 1976, or Tahvonen \& Salo, 2001). None of these alternatives will be compatible with both facts one and three simultaneously.

Assuming instead, like Gerlagh \& Liski (2011) do, that there is strategic interaction between a buyer and a seller of a resource, one may get a non-monotonic path for the price and scarcity rent. In general it will be hard to explain facts one and two by this model as it predicts an initial phase of rising prices and rents. Furthermore, although modeling the oil market as containing a strategic seller (OPEC) may be appropriate, ${ }^{4}$ the question remains whether there is any market power on the buyer side and, of course, for most other resources there is hardly any market power on any side. ${ }^{5}$

Now, what the previous models all have in common is that they assume that agents have an infinite time horizon. Yet it seems fair to say that there is little conclusive evidence showing how economic agents plan and make forecasts for the very long run. As the actual planning of agents is largely unobservable it is hard to say with any certainty whether they make approximately infinite plans and forecasts or whether they use some rule of thumb to simplify their long run planning. Thus, this paper has an approach in the spirit of Milton Friedman's black box (Friedman, 1953, Part I). In the absence of conclusive evidence of how agents plan, it simply compares two alternative assumptions - an infinite horizon and a rolling planning horizon - and evaluates their merits by how well they replicate the macroeconomic facts presented above.

A rolling planning horizon implies that agents make plans for only a finite future and that the plan is revised regularly. In each time period the representative agent makes a plan based on a maximization over a finite number of years while assuming that all other agents do the same. The first period of the plan is executed and a new plan is then formulated for an equally long future and so on.

Is this a common feature of how market participants make plans? Or is it more realistic to assume that they make infinite plans and forecasts? Some experimental evidence and casual observations, to be presented later, suggest a rolling horizon to be a reasonable

\footnotetext{
${ }^{4} \mathrm{~A}$ number of papers have shown that OPEC has market power but that it is much more limited than a classic monopolist's (Polasky, 1992; Barsky \& Kilian, 2002; Alhajji \& Huettner, 2000; Okullo \& Reynes, 2012),

${ }^{5}$ An explanation for fact three could be an increased demand for resources from countries such as China. However for this to hold one needs to assume that the market has been surprised by this demand as otherwise the no arbitrage condition of equal returns on capital and on keeping resources underground should have implied a price rising also before the demand materialized. Kilian \& Hicks (2012) show that this may indeed be possible and Hamilton (2009) discusses this possibility. However, this explanation stays silent about facts one and two.
} 
way of modeling. Yet the question remains whether this systematically occurs on the market. Judging by market outcomes there is little to guide us in this respect as earlier research has shown that rolling planning horizons replicate the infinite horizon outcomes in most standard dynamic macroeconomic models. ${ }^{6}$ But, while leaving other macroeconomic models intact, the rolling horizon assumption substantially changes the basic results of the Hotelling model with extraction costs in a way which reconciles the stylized facts presented above.

The intuition is as follows. With a large initial resource stock (or if the time horizon is short enough) a plan of extracting the whole stock within the time horizon would imply that the resource price would not cover the marginal cost of extraction. Hence, since total depletion is not optimal within the finite plan anyway, this essentially removes the scarcity consideration of the resource owner. Then, the extraction costs and the demand for the resource alone will determine the planned rate of extraction and the price forecast. The outcome, which is an implementation of the first period of a sequence of plans, will yield non-decreasing extraction and thus non-increasing prices for as long as the resource constraint is not binding within the horizon of the market - a situation which may prevail for a very long time. Furthermore, it will decouple price growth from the interest rate. This is shown in the paper, using the simplest possible model of exhaustible resources. By then adding technical change that pushes demand upwards we get an exponentially increasing extraction (which is another stylized fact of resource markets), and by improving the mining technology that reduces extraction costs, the resource price may even fall over long time periods. These results are in line with the first and second stylized facts above. Eventually, as the resource is being depleted, the total stock will be binding within the market's time horizon. At this point scarcity becomes a component of the price, thus raising it sharply, which also implies increasing profits over time. This can explain the third stylized fact above.

In order to test the alternative time horizon assumptions also quantitatively the model is calibrated to the oil market. The rolling horizon outcome then closely replicates the falling real oil price after WWII and accurately predicts the sharp price increase after 1998 up until today. However, it does not replicate the oil price shocks during the 1970's which were arguably due to other factors than scarcity (see, for instance, Barsky \& Kilian, 2002; Hamilton, 2003). In comparison, the infinite horizon model replicates the falling price for a few initial years but predicts an increase in the price occurring about 40 years earlier than what is observed in the data. ${ }^{7}$ These results suggest that, while oil prices may not have contained a scarcity rent historically, when it comes to the last decade and to future oil prices, scarcity probably plays an important role. This is in line with Hamilton's

\footnotetext{
${ }^{6}$ Kaganovich (1985) and Spulber (1991) have shown that a rolling horizon yields near optimal outcomes in capital accumulation models where the capital accumulation path looks qualitatively the same as in the standard model with an infinite horizon. It is also straightforward to verify that it does not have a qualitative effect on a model where an agent consumes an asset.

${ }^{7} \mathrm{~A}$ method for obtaining a prior guess of the time horizon, and a maximum likelihood estimate of the time horizon following the calibration, both suggest a time horizon of around 40 years for the oil market.
} 
(2009) conclusion which is based on more micro-economic observations. ${ }^{8}$ From a policy perspective this means that, for instance, tools to reduce $\mathrm{CO} 2$ emissions should take into consideration that oil scarcity probably plays an important role on the market today and accounts for a large share of the price (80-90 per cent according to the calibrated model).

Interestingly, even though a rolling horizon essentially is a form of bounded rationality, and even though it has a qualitative impact on exhaustible resource models, it is shown that this behavior is time consistent. In a rolling horizon world, resource prices and extraction are expected to be constant and this is indeed also the realized outcome for many years. So if rational expectations is an ability that grows out of a trial and error process, then rolling horizon resource owners will find no reason to alter their forecasting procedure for a long time.

An important question is what value, if any, economic agents assign to holding the resource stock at the end of their horizon. Under full uncertainty where, for instance the probability distribution is unknown, such a value needs to be formed through rules of thumb or guesses which are not necessarily correct even on average and cannot be verified ex ante. Roughly speaking, in terms of the model, adding a continuation value to the stock has no effect on the outcome as long as the value is not based on rational expectations. In fact, it may even strengthen the explanatory power of the model.

The paper starts by introducing the concept of rolling horizons in more detail and presenting some microeconomic observations that are in line with such behavior. By way of a simplistic model of exhaustible resources, section 3 presents the qualitative difference between a rolling horizon and a standard infinite horizon approach. It also shows what the possibilities are to improve one's planning over time by learning, addresses how a final stock value affects the results and analyzes what gains an agent could do by outsmarting the market. Section 4 calibrates the model to the oil market in order to investigate how it fits the historical price of oil. Finally, section 5 concludes the paper and discusses some welfare implications. The appendix contains a fairly large amount of supplementary material suitable for online publication.

\section{Introducing rolling horizon planning}

The idea that agents continuously update finite plans was first formalized by Goldman in 1968. The concept has been further explored in a few papers since then, mainly dealing with risk and stationarity (Easly \& Spulber, 1981) and optimality in settings of capital accumulation (Kaganovich,1985; Spulber, 1991). Generally, rolling horizon planning has been found to yield results fairly close to the optimal infinite time horizon when it comes to capital. Rolling horizons have also been analyzed in a game theoretic

\footnotetext{
${ }^{8}$ Note that Hamilton (2009) discusses both the possibility of increased prices due to increased awareness of finite resources (which essentially is what the model in this paper suggests) and due to increasing demand in developing countries. These two possibilities are of course not mutually exclusive and may work in conjunction.
} 
setting (Jéhiel, 1995) and have been extensively used within supply chain management research (e.g. Clark, 1998; Perea-López et al, 2003). Finally, in more recent papers, Caliendo \& Aadland (2007) and Findley \& Caliendo (2009) analyze retirement planning and social security under rolling horizons. There it is found that a rolling horizon can account for quantitative anomalies when it comes to saving behavior.

A finite planning horizon is meant to catch the notion that the further into the future we look, the more uncertain we are of what the possible outcomes are, what probabilities to assign to them and how to incorporate those eventualities into our planning today. Hence, this is not an issue of decision making under risk, where the probability distribution and outcome space is known, but rather of uncertainty where even assigning probabilities or knowing the workings of the market is hard. Facing this complexity and uncertainty it is conceivable that a rule of thumb may arise whereby agents make finite plans in line with the classical proverb "We'll cross that bridge when we get to it". It expresses the idea that people know that things will change in the future, but not exactly how, and that therefore there is no point in dealing with it now when the picture is unclear. The exact reason for the rise of finite plans can possibly be modeled in many ways. For instance, through ambiguity aversion (Gilboa \& Schmeidler, 1989), maximizing over the worst possible outcomes, sparsity based bounded rationality (Gabaix, 2011) or increasing the costs to forecasting (for a longer description, see Appendix A). In this paper, I will use the simplest possible assumption that makes it possible to analyze the macroeconomic effects of having finite plans. It will be assumed that agents, as a rule of thumb in order to cope with increasing uncertainty or computational complexity, maximize over a finite number of years and that they have fully certain and correct knowledge of exogenous factors within their horizon of maximization. This is admittedly a very crude way of modeling, but it contains no obvious bias (compared to explicitly micro-modeling this behavior) since it catches the driving mechanism that plans are finite. It should be emphasized that having a risk component which is increasing the further into the future one looks will not have the same qualitative effects as having finite plans. Similarly if agents perceive that, at some future period, with positive probability the parameters of the market change from being known to being unknown. The reason is that, in both these alternative cases, the owner is including infinite time contingencies. But if agents truncate the planning horizon following such complexity the results of this paper hold. So, adding such components on top of finite plans will not change the qualitative results presented here.

Graphically, the rolling horizon concept is presented in Figure $2 .{ }^{9}$ At a point in time $(q)$ the economic agent receives perfect information for the coming $T$ time periods (by perfect information is meant that they know the true outcome of exogenous variables, parameters and functional forms). The agent makes a plan for the next $T$ time periods with the aim of maximizing the aggregated discounted utility from consumption, subject to some intertemporal constraints, today's state variable(s) and some terminal conditions.

\footnotetext{
${ }^{9}$ For a formal description see Appendix A.
} 


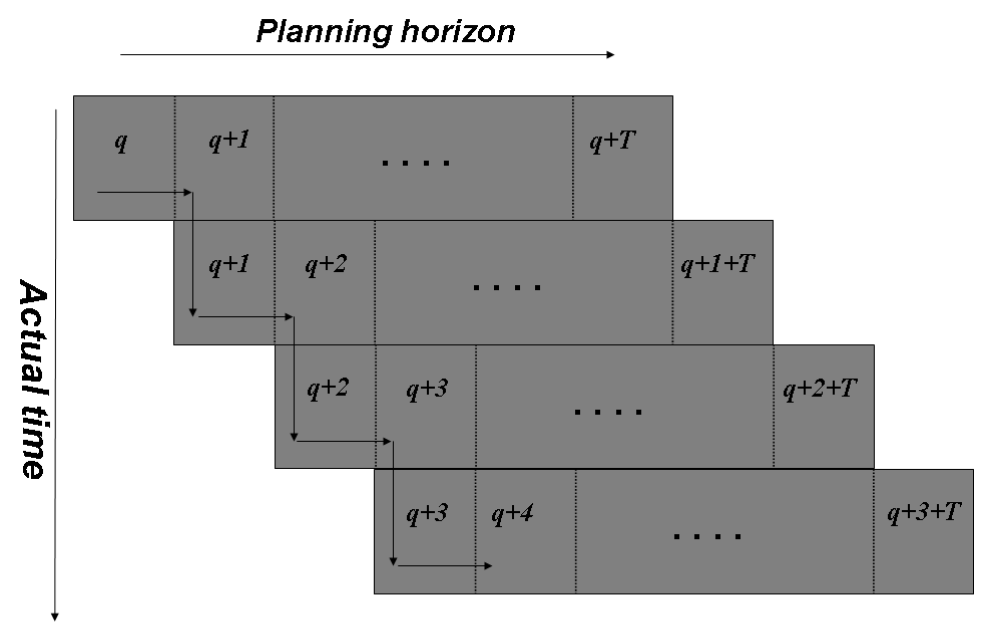

Figure 2: Schematic of a rolling horizon. Each horizontal rectangle is a plan. The outcome is the diagonal formed by the first period of each plan.

As part of this plan, a forecast of endogenous variables up to time $q+T$ is made (most notably prices) and used in solving the finite maximization problem. The forecast is done assuming that all other agents also maximize over finite time. The agent then implements the first period of the plan which also determines the state variable(s) for the next period. A new plan is then formed encompassing the time interval from $q+1$ to $q+1+T$ taking the state variable(s) as given. The writing of plans and execution of the first period of each plan sequentially rolls on to infinity. One interpretation is that $T$ is a measure of bounded rationality where we converge to the fully rational case as the horizon goes to infinity. An important detail to note is that today's plan does not rely on the plans to be made in the future. ${ }^{10}$

A subtlety in modeling rolling horizons is that the terminal conditions may be as important as the finite time horizon itself. In both a social planner setting and a decentralized setting this can be manifested through the beliefs about the continuation value of the assets at the end of the horizon (in terms of market value or in terms of welfare). Now, when having no information about the distant future, whether and how to include an unverifiable future asset value must essentially be based on rules of thumb. To the extent that agents want to include the continuation value in their business plan, their estimation of this must therefore be based on a guess, which will not necessarily be correct even on average. For most of the analysis the imposed final asset value will be zero. But also the case of a positive final asset value will be analyzed. The general equilibrium price forecast

\footnotetext{
${ }^{10}$ The underlying motivation for finite maximization is information uncertainty and computational complexity. To make plans contingent on future plans then seems unreasonable given that this would necessitate the same amount of information and entail even more complexity than making an infinite plan in the first place. Technically, plans contingent on plans is the same as overlapping generations and will yield the same results as an infinite horizon when applied to an exhaustible resource model (see Agnani et al, $2005)$.
} 
within the planning horizon must then be consistent with this terminal constraint. ${ }^{11}$

There are many casual observations of economic behavior consistent with rolling horizons. For instance, business plans of firms are always stated in finite time and updated regularly. Another example is that of US social security. On an annual basis, the solvency of the social insurance system over the next 75 years is updated in a report (e.g., Board of Trustees, 2009). These forecasts and business plans are of course written today in knowing that they will be updated again next year. Moreover, most government budgets are specified for a year or two at a time (for more examples, see Easly \& Spulber, 1981). Another suggestive piece of evidence is that futures markets for commodities such as oil seldom span more than a few years into the future.

Furthermore, in discussions I have had with representatives of oil companies it comes clear that, not only are they using very high interest rates when calculating future profits, but they do not start any new projects which do not yield expected profits within 15-20 years. This suggests that stocks left in the ground after this time has a very low value for them, if any. So, if scarcity is considered by anyone, it should be from the point of view of the original owner - i.e. the government or state. But in interviews I have conducted with Scandinavian government resource owners, they state that the distant future is so uncertain that there is no point in including it in a business plan. They further say that it would be bad policy to deliberately save resources for an uncertain future and that they extract as long as the price covers their (marginal) costs of extraction.

There is also plenty of experimental research suggesting that there are limitations to how far ahead people plan and that, when making finite plans, they assign no or low (and certainly not any rational) value to outcomes beyond their horizon. Most conducive to the subject of this paper is a recent study by van Veldhuizen \& Sonnemans (2011). They show experimentally that when subjects have access to a large stock of exhaustible resources, they tend to ignore the dynamic issue of resource allocation more than what is prescribed by rationality. Although it is hard to say anything conclusive about how agents plan for the distant future and although the previous examples may well be consistent with other stories, they at least warrant an exploration of how finite plans would affect macroeconomic outcomes. For a review of other experiments and a further discussion of issues related to rolling horizons, see Appendix A.

\section{$3 \quad$ Natural resource extraction with rolling horizons}

\subsection{Basic results}

This section will present the simplest possible model that illustrates why the choice of time horizon is of importance in resource models. The results can be generalized by enriching the model across several dimensions (see Spiro, 2012). As a benchmark, consider an

\footnotetext{
${ }^{11}$ Since the terminal constraint is based on a guess it must not necessarily itself be based on a general equilibrium outcome.
} 
infinite horizon resource extraction model with extraction costs and a mass 1 of identical profit maximizing resource owners.

$$
\begin{gathered}
\max _{\left\{E_{t}\right\}_{t=0}^{\infty}} \sum_{t=0}^{\infty} \frac{1}{R^{t}} \pi_{t} \\
\pi_{t}=p_{t} E_{t}-M\left(E_{t}\right) \\
S_{t+1}=S_{t}-E_{t} \\
S_{t+1} \geq 0 \\
S_{0} \text { given, } R>1 .
\end{gathered}
$$

The representative resource owner aims at maximizing the discounted profits by selling an exhaustible resource $(E) . \quad p$ denotes the resource price after extraction. The cost of extracting the resource, $M(E)$, is strictly increasing, weakly convex and $M(0)=$ 0 . The stock of the resource $S$ is depleted at the speed of extraction, and there is a resource constraint stating that the stock cannot go below zero. $R$ is the return on other investments (i.e., $R-1$ is the interest rate) and is exogenous and constant for conciseness. For brevity, the production sector of the model will be modeled as sparsely as possible. Production in the economy, $F(E, L)$, is done using an exhaustible resource $E$ and labor $L$ by competitive firms owned by the representative agent who also owns the resource and who supplies the labor. $F$ has constant returns to scale but decreasing returns in any one argument. For the remainder of the treatment of this basic model it will be assumed that $L=1$ and so will be dropped from the equations. Hence, by perfect competition follows that the price in equilibrium has to equal the marginal productivity of the resource in any time period.

$$
p=F^{\prime}(E)
$$

Taking the first-order conditions of the resources owner, this problem yields

$$
\frac{p_{t+1}-M^{\prime}\left(E_{t+1}\right)}{p_{t}-M^{\prime}\left(E_{t}\right)}=R
$$

which together with equations (2), (3) and (6) gives the classic Hotelling result. ${ }^{12}$ That is, due to the discounting of future profits, the solution displays falling extraction while the resource price (in equilibrium determined by the marginal productivity) is increasing over time. More precisely, equation (7) shows that the price net of marginal extraction costs should rise at the rate of interest.

Next we examine a one shot finite time version of this problem, again with competitive firms using the resource as input in production and a representative agent owning it. The formulation is seemingly similar. Let $q$ denote the current year and $T$ the number of

\footnotetext{
${ }^{12}$ See, for instance, Dasgupta \& Heal (1974) or, any textbook in resource economics for how to derive these results.
} 
future years over which to maximize.

$$
\begin{gathered}
\max _{\left\{E_{t}\right\}_{t=0}^{T}} \sum_{t=0}^{T} \frac{1}{R^{t}} \pi_{q+t} \\
\pi_{q+t}=p_{q+t} E_{q+t}-M\left(E_{q+t}\right) \\
S_{q+t+1}=S_{q+t}-E_{q+t} \\
S_{q+t+1} \geq 0 \\
S_{q} \text { given, } R>1 .
\end{gathered}
$$

The description of the solution to this problem will be made heuristically here while the formal derivation is in Appendix B. In contrast to the infinite horizon case, there can now be two possible outcomes of the problem. If the stock is large enough, or the time horizon short enough, or the cost of extraction high enough, it will not be optimal to deplete the whole stock within $T$ years. To see why, note that within any one time period there is a maximum extraction rate $E_{\max }$ which induces the maximum profits. This is due to the fact that the marginal cost of extraction will surpass the marginal productivity of the resource if extraction is very high. Thus, we can implicitly define $E_{\max }$ as follows.

$$
E_{\max } \equiv\left\{E: M^{\prime}(E)=F^{\prime}(E)\right\}
$$

Due to convexity of $M$ and concavity of $F, E_{\max }$ is uniquely defined. Then, over $T$ years, the maximum aggregate extraction is simply $T E_{\max }$. If the stock, $S_{q}$, is larger than this, it will not be optimal to extract it all. In effect, the resource constraint $\left(S_{q+t+1} \geq 0\right)$ will not be binding. In this case, it is optimal to extract exactly $E_{\max }$ every time period. In equilibrium, with perfect competition on the demand side, we get that

$$
p_{q+t}=F^{\prime}\left(E_{q+t}\right)
$$

which with (13) gives the price

$$
p_{q+t}=M^{\prime}\left(E_{\max }\right)=F^{\prime}\left(E_{\max }\right) \forall t \in 0 \ldots T .
$$

This implies that extraction will be constant over time as will the price. The other alternative is if the stock is small enough to be fully depleted within $T$ years. That is, if $T E_{\max }<S_{q}$. Then, the resource constraint will be binding and the solution will be qualitatively similar to the infinite horizon problem where extraction is falling and the resource price is increasing over time (see the proof of Lemma 1 for the derivation of this equation).

$$
\frac{p_{q+t+1}-M^{\prime}\left(E_{q+t+1}\right)}{p_{q+t}-M^{\prime}\left(E_{q+t}\right)}=R
$$


A useful lemma summarizes these results.

Lemma 1 Consider a finite time resource extraction problem of length $T$. If and only if $S_{q} \geq T E_{\max }$ then $E_{q+t}=E_{\max }$ and $p_{q+t}=M^{\prime}\left(E_{\max }\right)$ for all $t \in\{0,1, \ldots, T\}$. If and only if $S_{q}<T E_{\max }$ then $E_{\max }>E_{q+t}>E_{q+t+1}$ and $M^{\prime}\left(E_{\max }\right)<p_{q+t}<p_{q+t+1}$ for all $t \in\{0,1, \ldots, T-1\}$.

Proof. See Appendix B.

The rolling horizon version of the problem is a sequence of finite time plans where the first year of each plan is executed before a new plan is made, taking the current stock level as given. This means we can apply problem (8)-(12) and Lemma 1 sequentially to get the rolling horizon outcome. The notation now will be that $x$ represents a planned variable and $\tilde{x}$ represents a realized variable.

If the initial stock, $\tilde{S}_{0}$, is high enough, the resource constraint will not be binding and the plan will be to extract so that the marginal cost of extraction is equal to the resource price, forecasting that the resource price equals its marginal productivity - as given by (14). The realized extraction, which is equal to the extraction of the first period of the plan, is then at time zero $\tilde{E}_{0}=E_{\max }$ and the price will simply be $\tilde{p}_{0}=M^{\prime}\left(E_{\max }\right)$. The next period, provided that the stock is still large enough $\left(\tilde{S}_{1}=\tilde{S}_{0}-E_{\max } \geq T E_{\max }\right)$, will yield an identical plan as in the previous period and thus the same outcome: $\tilde{E}_{1}=E_{\max }$ and $\tilde{p}_{1}=M^{\prime}\left(E_{\max }\right)$. Similar plans and forecasts will be formulated annually and the first year of each plan will be executed, which implies the dynamic outcome of constant extraction and prices. During this phase there will be no connection between the price growth and the interest rate (as represented by $R-1$ in this simplistic model). It will continue in this way for as long as $\tilde{S}_{q} \geq T E_{\max }$. That is, until the stock becomes small enough to be depleted within $T$ years which may be a very long time. At this point, the new plan will change character to include the binding resource constraint implying falling extraction - as in (16). In the next period, the stock will be smaller, thus necessitating lower planned extraction and so on. This phase therefore yields the outcome of falling extraction and increasing prices. The results for the rolling horizon model are summarized in the following proposition.

Proposition 1 Consider a resource extraction model with a rolling planning horizon of length $T$. If $\tilde{S}_{0}>T E_{\max }$ then:

1. Initially, for $\left\lfloor\frac{\tilde{S}_{0}-T E_{\max }}{E \max }\right\rfloor$ consecutive time periods, the extraction will be constant at $\tilde{E}_{q}=E_{\max }$ and the price will be constant at $\tilde{p}_{q}=M^{\prime}\left(E_{\max }\right) \cdot{ }^{13}$

2. Initially, for $\left\lfloor\frac{\tilde{S}_{0}-T E_{\max }}{E \max }\right\rfloor$ consecutive time periods, the price and profits will be independent of the interest rate and the profits will be strictly positive.

\footnotetext{
${ }^{13}$ The notation $\lfloor x\rfloor$ denotes the floor of $x$ to represent that the statement regards a discrete number of time periods.
} 

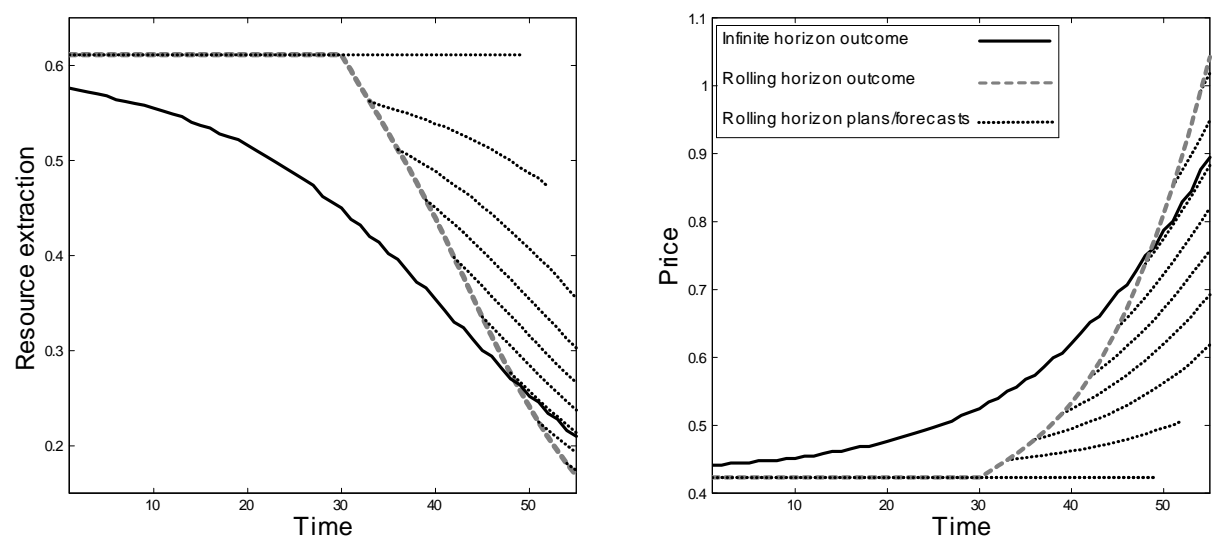

Figure 3: An exhaustible resource model with a rolling horizon of 20 years compared to a model with infinite time horizon. Note that some rolling horizon plans and forecasts have been deleted for expositional reasons.

3. At time $q=\left\lfloor\frac{\tilde{S}_{0}-T E_{\max }}{E \max }+1\right\rfloor$ and beyond, the extraction will be decreasing, the price will be increasing and profits per unit will be increasing.

\section{Proof. See Appendix B.}

These results are visualized in Figure 3. In total, the results of the infinite horizon and the rolling horizon version of the problem are qualitatively different. This is because, in the latter, extraction and prices may be constant for a significant period of time. Once the shift to the second phase occurs, the results are qualitatively similar to those of an infinite horizon. But the rolling horizon problem has a more quickly decreasing extraction and more quickly increasing resource prices. This is largely due to the fact that the economy must now cope with a smaller stock of resources following the overextraction in the early years.

As can be seen, the proposition replicates the stylized facts presented in the introduction. There is however one detail which the model needs to be extended in order to explain. The empirical observations speak of an extraction which is increasing over time and a price which may be decreasing. To obtain such results, it is enough to add some technological improvements to the extraction technology. This is easiest seen in equation (15). An improved technology will lower the extraction costs thus lowering the price and increasing the extraction during the first phase. ${ }^{14}$ By adding various components - such as capital, labor augmenting and resource augmenting technology - we can obtain a more realistic model. For a formal treatment of this and a few more enrichments of the model see Spiro (2012). The outcome of such a model is illustrated in Figure 4. To the left of the vertical line on each graph we see the outcomes of the first phase. This is arguably where

\footnotetext{
${ }^{14}$ Naturally, falling extraction costs will also depress the price trend in the infinite horizon model. However, to get falling prices in the infinite horizon model, harder constraints need to be imposed on the extraction technology.
} 
the world has been for the last century. As can be seen, the main results, that extraction increases exponentially while the resource price is constant or falling, is maintained. The general features of the model in this phase replicate also the standard stylized growth facts that output, capital, consumption and labor wage are growing and that the interest rate is roughly constant. This illustration also shows, to the right of the vertical line, the economy may regress for an intermediate period when the resource constraint starts binding. The extent of this effect depends on how essential the resource is in production (and possibly also on endogenous technical change which is not modeled here).
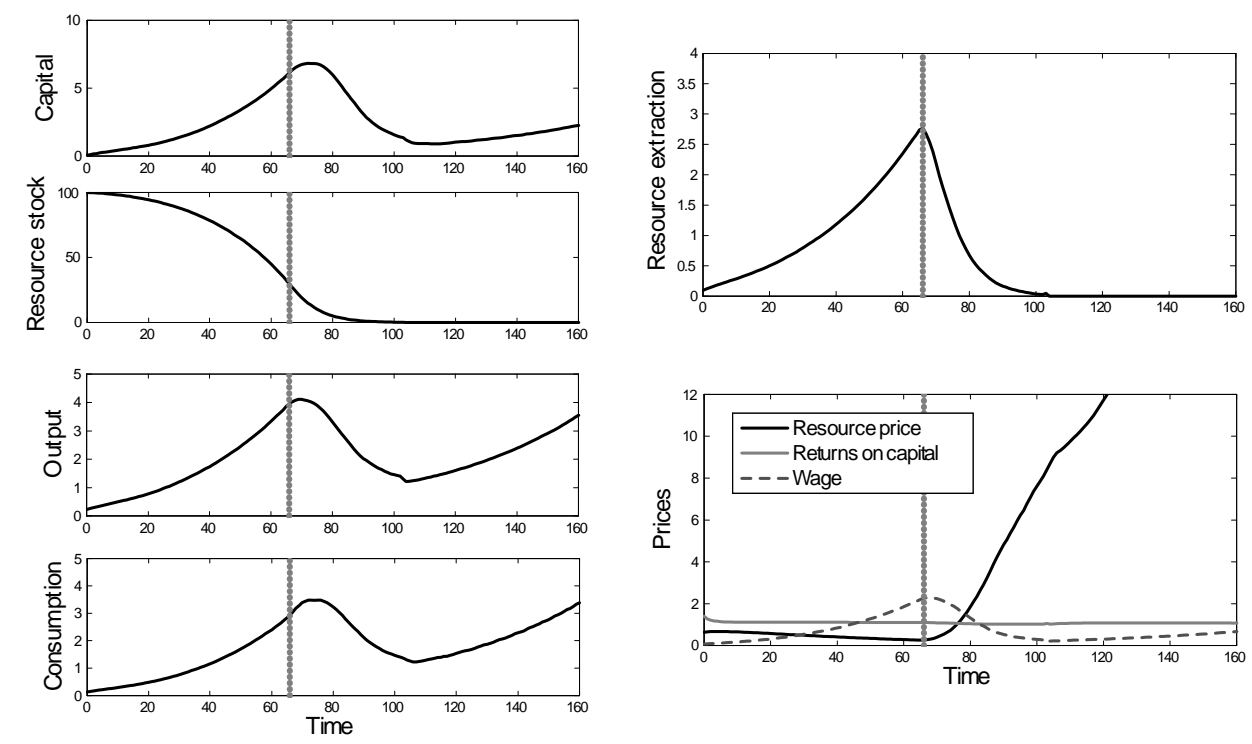

Figure 4: A ten-year horizon economy's evolution over time. The vertical line marks the shift from a non-binding to a binding resource constraint.

\subsection{Time consistency and learning}

A common discussion in economics is whether certain behavior and beliefs are rational. One argument for imposing rationality on beliefs and behavior is that, over time, agents would learn from their mistakes and eventually form beliefs which are rational (i.e. stand the test of time) and thus also choose behavior that, at least in expectational terms, maximizes their objective function so that they are right "on average". ${ }^{15}$ Since the motivation for modeling rolling horizons mainly comes from information constraints (rather than a lack of care for the future), this notion of rationality is important to address. Put differently, if agents constantly notice that their forecasts are wrong they may learn from this and improve the accuracy of their forecasts over time - for example by extending the time horizon. So the question is to what extent rolling horizon agents will actually make wrong forecasts and plans.

\footnotetext{
${ }^{15}$ In other settings, time inconsistency may be embedded in the preferences of agents. For example, as modeled by hyperbolic discounting leading to "games against selves" (see Krusell \& Smith, 2003).
} 
If beliefs (i.e. the price forecast) and planned actions (i.e. control variables) are in line with later observed outcomes, I will refer to rolling horizons being "immune to learning". In a sense this catches the spirit of self-confirming equilibria (e.g. Fudenberg \& Levine, 1993). The main idea is to capture that agents on an aggregate level may be on a nonoptimal path, but that they may not have any reason to suspect that some other actions are better since their beliefs are always fulfilled. To see whether agents are immune to learning, one essentially asks if and after how long agents get the opportunity to realize that their plan and forecast was not realized as expected. Applying this notion of learning to the rolling horizon model yields the following proposition.

\section{Proposition 2 Rolling horizon behavior in an exhaustible resource model is:}

1. Immune to learning throughout the first phase (i.e. for as long as $\tilde{S}_{q} \geq T E_{\max }$ ).

2. In the second phase (i.e. when $\tilde{S}_{q}<T E_{\max }$ ) not immune to learning.

\section{Proof. See Appendix B.}

The proposition shows that as long as the economy remains within the first phase (when the resource constraint is not binding) agents will not be proven wrong and will thus be immune to learning. This is due to the fact that prices are forecast to equal marginal extraction costs which is also what is realized for many years. This becomes clear in Figure 3. In the left figure the extraction plans are depicted along with the realized extraction. There we see the outcomes are equal to the plans for the first 30 time periods. Likewise, in the right part of the figure, one can see that the price forecasts equal the realized price during the first 30 time periods. It implies agents will not get any signals that they need to improve their forecasting since they turn out to be correct. This will proceed for as long as the economy is in a state where the resource constraint is not binding. ${ }^{16}$ That is, any planned action and forecasted price that falls within the first phase will also be materialized. For sufficiently early current time periods $q$ this encompasses the whole plan (from $q$ to $q+T$ ). However, it does not continue when the resource constraint eventually starts binding. Then, rolling horizon behavior will not be immune to learning. This is due to the fact that in the next plan, extraction is revised downwards and the price forecast revised upwards. This can be seen in Figure 3 - when the extraction rate falls the plan lies above the realization. This non-immunity to learning also affects forecasts made before the switch of phases but which regard outcomes after the switch. But the main point is that such mistakes will not be realized until the change of phases actually occurs.

A noteworthy and possibly counter-intuitive implication of the results above is the reversed connection between outcomes under different horizons and opportunities to learn

\footnotetext{
${ }^{16}$ Note that this also holds for an exhaustible resource model that incorporates exogenous technical change in extraction and/or production, as long as agents have correct expectations of technical advancement within the time horizon.
} 
from mistakes. When the observable outcomes of a rolling and an infinite horizon are qualitatively similar (in the second phase), then agents will have the chance of realizing that plans are biased when using rolling horizons. But when the qualitative results do differ between the rolling and the infinite horizon (in the first phase), then agents will not get the opportunity to learn since they are not proven wrong. ${ }^{17}$

When the economy reaches the change of phases, agents will start receiving signals that a short horizon yields inaccurate predictions. This also coincides with an increase in welfare losses as a numerical analysis suggests that the closer one is to the change of phases, the larger are the losses. Although being outside of the model, it then is conceivable that over time agents may try to lengthen their forecasts to horizons such that the profit losses are small. Another thought experiment is to think about a case where one agent insists on using an infinite horizon herself but does not realize everyone else is using a finite rolling horizon. This agent will forecast prices to rise while in fact they will stay constant - her forecast will be systematically biased. Hence being fully rational, but not realizing everyone else is not, will make for more mistakes in forecasting than being as boundedly rational as everyone else. The next section contains a treatment of an infinite horizon agent which understands everyone else has a finite horizon.

\subsection{Terminal constraints, end values and profits losses}

This section will analyze how the rolling horizon results change when using alternatives to the assumption of no end value of the stock, when extending the horizon and will also analyze prospective profit losses.

By letting $T$ grow, the results of the rolling horizon model will eventually converge to the case of an infinite horizon. This can, for example, be seen in Proposition 1 which, as $T$ increases, converges to its infinite horizon counterparts. When $T$ grows sufficiently, the initial endowment $S_{0}$ must necessarily be smaller than $T E_{\max }$. The first phase then disappears. Furthermore, if we use a resource constraint stating that the stock cannot go below a certain threshold $\left(S_{\min }\right)$ which is large enough, then it is possible to get a rolling horizon environment which is similar or even more conservationist than in an infinite horizon case. If, on the other hand, $S_{\min }$ is small enough or if the rule of thumb is to leave a certain, small enough, fraction of the stock at the end, the original rolling horizon results go through qualitatively.

A more subtle result is if we let the final stock have a value. Agents may use this value as a rule of thumb to proxy for scarcity or a longer horizon. Now a representative owner with a rolling horizon makes a plan for extraction covering the next $T$ years also considering that there is some price, $P_{q+T+1}$, to every unit of the stock left in the ground

\footnotetext{
${ }^{17}$ A striking example of this is Simon's (1996) claims. Historically, people that have ignored scarcity in their forecasts have turned out to be more correct than people that have considered resource scarcity to be a factor. Thus, according to Simon, the best way of making forecasts on the resource markets is by ignoring scarcity.
} 
at the end. Thus, in creating the plan, the following problem will be solved.

$$
\begin{gathered}
\max _{\left\{E_{q+t}\right\}_{t=0}^{T}} \sum_{t=0}^{T} \frac{1}{R^{t}}\left[p_{q+t} E_{q+t}-M\left(E_{q+t}\right)\right]+\frac{1}{R^{T+1}} P_{q+T+1}\left[S_{q}-\sum_{t=0}^{T} E_{q+t}\right] \\
S_{q+t+1}=S_{q+t}-E_{q+t} \\
S_{q} \text { given, } S_{q+t} \geq 0, F(t)=F(E(t)), R>1
\end{gathered}
$$

To solve this problem, we need to make an assumption on how $P_{q+T+1}$ is determined. Given that a rolling horizon is motivated by a lack of information regarding events beyond $T$, the case of an exogenous unit price will be analyzed first. Then, the case of an endogenous unit price, which is determined by the size of the aggregate stock, will be analyzed.

When the continuation value is exogenous, there may be two types of outcomes from this problem. The first case is just a straightforward maximization which yields the following plan and forecast.

$$
\begin{aligned}
p_{q+t}-M^{\prime}\left(E_{q+t}\right) & =\frac{1}{R^{T-t+1}} P_{q+T+1} \quad \forall t \leq T \\
p_{q+t} & =F^{\prime}\left(E_{q+t}\right)
\end{aligned}
$$

For the functional forms specified earlier in Section 3, this implies an extraction plan that is decreasing over time. What the unit end value $P_{q+T+1} / R^{T-t+1}$ does is pushing a wedge between marginal productivity and marginal extraction, a wedge that is growing with $t$. However, and perhaps more important to note, the planned extraction in some future period is determined independently of the planned extraction in other periods. This is due to the current assumption that the unit price $P_{q+t+1}$ is independent of the size of the remaining stock at time $T+1$. Thus, the rolling horizon outcome, i.e. the implementation of the first period of each plan, is simply

$$
F^{\prime}\left(\tilde{E}_{q}\right)-M^{\prime}\left(\tilde{E}_{q}\right)=\frac{1}{R^{T+1}} P_{q+T+1}, q=0 \ldots \infty .
$$

From this expression, it is clear that the time path of realized extraction is determined by the time path of $P_{q+T+1}$. As an example, consider the case of a constant final unit value. This can be the counterpart to believing that there is some fixed unit price for selling the mine at the end of the horizon as a rule of thumb to roughly capture that there is some scarcity. In this case, the realized extraction will remain constant over time, just like in the case of no final value of the stock. Naturally, this also implies a fixed realized resource price. If $P_{q+T+1}$ is decreasing with $q$, then extraction will increase over time and vice versa. Moreover, the level of $P_{q+T+1}$ has no effect on the time trend. Thus, even if the market's guess of $P_{q+T+1}$ is a gross overestimation of the value that will eventually be observed, this has no effect on the trend.

Eventually, the nature of the solution must change, which leads to the second type 

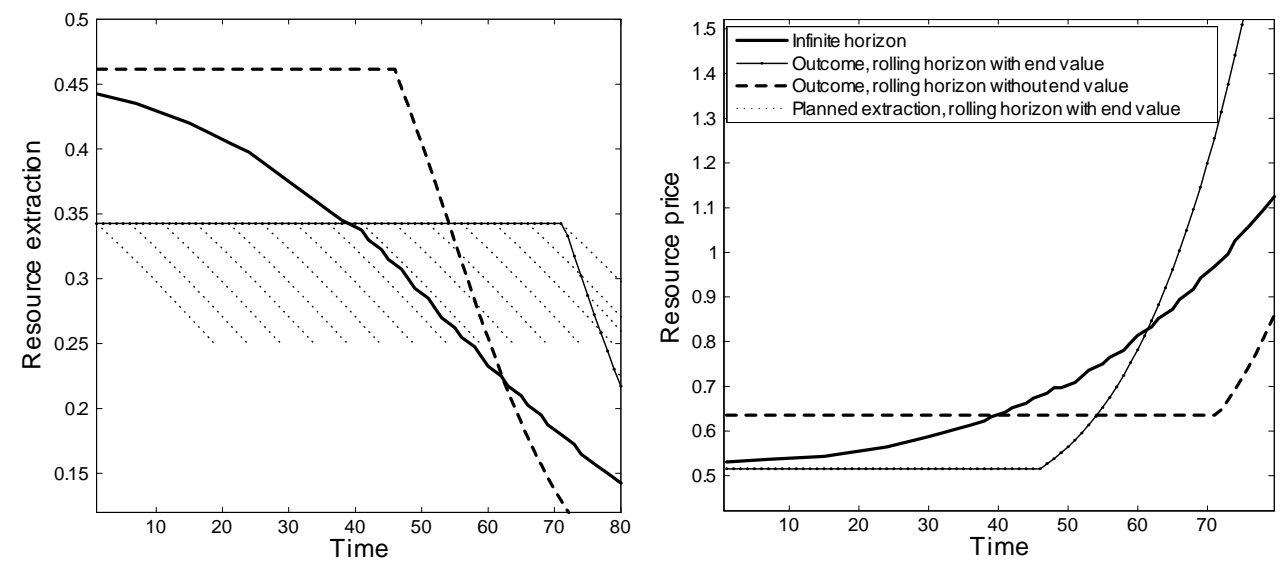

Figure 5: Simulation of an exhaustible resource model with a rolling horizon of 20 years and a constant end value of the stock.

of outcome. Previously, the non-negativity constraint $\left(S_{q+t} \geq 0\right)$ was not binding since the final value kept extraction low enough. However, eventually, the plan will imply that there will be no remaining stock at time $T+1$. Thus, every plan will look like a standard Hotelling model with a finite horizon and a binding resource constraint. Then, since the realized stock is falling over time, the realized extraction will fall and the price will increase.

The total realized outcomes are displayed in Figure 5. Here, a constant and fairly high end value is used and thus extraction is initially lower than what would materialize in an infinite horizon case. However, extraction remains constant and only starts falling after many years. It should be noted that it remains constant for longer than in the case of a rolling horizon with no end value. In fact, the higher the end value, the longer constant extraction will be upheld. A qualitative difference of adding an end value is that the plans in the first phase now dictate falling extraction over time, while the realized extraction is constant. Hence, time consistency is no longer maintained when an exogenous end value is added.

Up until now, the representative resource owner took the end value as an exogenous guess. If the end value is instead endogenous to the problem, the rolling horizon result may no longer hold. In particular, if $P_{q+T+1}$ is based on perfect information until infinity it becomes a function of the stock. ${ }^{18}$ This function perfectly incorporates all future profits of the resource and the rolling and infinite horizon cases therefore perfectly align. Hence, with the risk of stating the obvious, assuming a finite horizon with a rationally estimated end value is the same as assuming an infinite horizon, as a calculation of the end value requires correct estimates of the resource price until infinity.

An overall conclusion from the previous analysis is that adding a continuation value

\footnotetext{
${ }^{18}$ The total continuation value is equal to all discounted future profits of the resource, $P_{q+T+1} S_{q+T+1}=$ $\sum_{t=1}^{\infty} \frac{1}{R^{t-1}}\left[p_{q+T+t} E_{q+T+t}-M\left(E_{q+T+t}\right)\right]$.
} 
does not in itself undermine the main rolling horizon results of constant extraction and prices. Rather, it depends on how this value is changing over time and thus how it is formed. If agents rationally calculate the continuation value, then we get increasing prices. But if they routinely just attach some final unit value to roughly catch that there is a future market, constant prices and extraction may be realized during a long time. It can be noted that when a rolling horizon is coupled with a zero continuation value, it is not the zero value by itself that drives the results but rather the consequential assumption that when the value is zero it is also constant. Adding an end value also reestablishes a connection between the price and the interest rate but in a different way to the standard infinite horizon model. While the infinite horizon model implies a positive connection between price growth and the interest rate level, a rolling horizon model with an exogenous end value implies a negative connection between the price level and the interest rate level. ${ }^{19}$

A final discussion is that of potential welfare losses. Comparing the welfare of a world using rolling horizons with one of infinite horizon is analytically hard. However, a numerical analysis suggests that one either needs a very short time horizon or unrealistic parameter settings for losses to be large. ${ }^{20}$ For example, a time horizon of 35 years consistently yields losses on a level of less than 2 percent. ${ }^{21}$ The reason for the losses being small is that with a rolling horizon, consumption is initially higher than with an infinite horizon. For example, in Figure 5, it takes over 60 years for extraction under a rolling horizon to fall below the infinite horizon counterpart. For subsequent losses to have an effect, economic agents need to be either very patient or very inclined to consumption smoothing (e.g., $\sigma>5$ in a CRRA utility function). For standard values of discounting (3-7\%) and concavity of the utility function $(\sigma \leq 3)$ and for reasonable horizon lengths $(T \geq 20)$ and for initial resource stocks such that extraction is non-decreasing for 50 years or more, the welfare losses remain below three percent and mostly well below that. ${ }^{22}$ However, as we approach the switch of phases, welfare losses from then onwards

\footnotetext{
${ }^{19}$ One of the early empirical papers, by Heal \& Barrow (1980), finds a positive connection between price growth and the growth of the interest. That is, $\frac{p_{t+1}}{p_{t}}=\alpha \frac{R_{t+1}}{R_{t}}$ where $\alpha>0$. One possibility is that this result is driven by a negative correlation between $p_{t}$ and $R_{t+1}$. This would be consistent with the prediction in the rolling horizon model with end values where a high expected return in the future lowers the price today. To substantiate such a claim one would of course need to test it with data.

${ }^{20}$ In the simulations, I have used a CRRA utility function (i.e. not just profits) varying $\sigma \in[0,5]$; the cost function $M=\frac{E^{\theta}}{A m}$ varying $\theta \in[1,4]$; a concave production function $F=A E^{\alpha}$ letting $\alpha=.3$ mainly but vary the technology ratio $A_{m} / A \in[1,4]$; a discount factor of 0.95 so that every period should be interpreted as a year; vary the horizon $T \in[5,35]$. Then, I vary the initial stock so that the phase of constant prices lasts between 0 and 100 years.

${ }^{21}$ Note that in this calculation a zero final value of the stock has been used. A small but positive final value would decrease these losses. This is since, with no end value, losses come from overextraction in the early periods generating too much scarcity later. The final value dampens the early overextraction and hence the problem of scarcity is decreased later. However, a very high final value could increase losses, but then due to it inducing too conservationist behavior in the beginning.

${ }^{22}$ Most likely, this is an upper bound since the losses are driven by the convergence of consumption to zero over time - i.e. the rolling horizon model converges to zero more quickly than does the infinite horizon model. In a model with a renewable substitute, there will be a lower bound for consumption implying that the losses should be more limited than here. Resource augmenting technical change should
} 
are increased. Hence the real cost of using rolling horizons becomes eminent only when scarcity is (soon to be) apparent for the resource owner.

However, such a comparison may not be the only relevant way of thinking about incentives for deviation from rolling horizons. This is since a single resource owner cannot change the whole market but rather only its own extraction path. Another way of addressing the issue of gains and losses is therefore to ask what welfare gains a single and small agent with an infinite horizon can make given that she knows that everyone else has a rolling horizon. This would also capture the economic incentives for learning. For specific parameter settings, it is possible to get very large gains. For most parameter combinations, however, and for those that are the most realistic, the gains remain at levels of $0.5-5 \%$ (see footnote 20 for parameter details). This should also be treated as an upper bound as the absence of a substitute makes consumption converge to zero over time. The main reason for the moderate gains is that the additional profits of an infinite horizon can only be realized far into the future. When prices remain constant for nearly a century, the later gains of having a larger stock once prices do start rising are effectively discounted away. This also implies that an agent that is outsmarting the market by having a longer horizon will nevertheless extract at a growing rate if everyone else is doing so. ${ }^{23}$ Considering that anything that approaches a reasonable accuracy about the infinite horizon requires insights about the very far future and extreme computational ability and considering that outsmarting the market would require more computational ability than just being an infinite horizon agent out of many others, one comes back to the question whether agents get signals regarding the quality of their plans. As was shown in section 3.2, during the first phase, agents will consistently make correct forecasts which implies that there will be no signals alluding to there being a better way of planning one's resource extraction.

\section{Calibration to the oil market}

This section aims at testing whether the model fits the price and extraction of oil for the period 1949-2009. For this, a more comprehensive model than the stylized one used earlier is needed. In particular, a richer, CES, production function including capital $(K)$, labor $(L)$, labor augmenting technology $\left(A_{L}\right)$, energy saving technology $\left(A_{E}\right)$ and a substitute for oil $(N)$ is now added. ${ }^{24}$ The technology in oil extraction $\left(A_{M}\right)$ is also allowed to

\footnotetext{
have a similar effect.

${ }^{23}$ See Spiro (2012) for details. Note that these simulations were made under the assumption that the resource owner that outsmarts the market is infinitely small so that its actions will have no effect on the market equilibrium. A large agent with investment capacity would buy up the rolling horizon agents' resource stocks thereby affecting the equilibrium price path. With sufficient investment capacity we would end up with an infinite horizon market price and extraction path.

${ }^{24}$ While $N$ is not needed for the theoretical results, it is needed for a credible calibration as, clearly, there are substitutes for oil in the form of coal, gas and ultimately also nuclear, solar power etc. While the degree of substitutability with oil may differ between these alternative sources, in a long run analysis such as this, it seems reasonable that substitutability should be high for all of them.
} 
change over time. In every year $q$ a representative agent solves the following problem choosing extraction $(E)$ and forecasting the resource price, interest rate and labor wage while taking the rest of the variables as exogenous. An analytical treatment of this model can be found in Spiro (2012).

$$
\begin{aligned}
& \max _{\left\{E_{t}\right\}_{t=0}^{T}} \sum_{t=0}^{T} \beta^{t} \frac{C_{t}^{1-\rho}}{1-\rho} \text { s.t. } \\
C_{q+t}+K_{q+t+1}= & p_{q+t}\left(E_{q+t}+N_{t}\right)+r_{q+t} K_{q+t}+w_{q+t}-M\left(E_{q+t}\right)+(1-\delta) K_{q+t} \\
S_{q+t+1}= & S_{q+t}-E_{q+t} \\
S_{q+t+1} \geq & 0 \\
H_{q+t} & =\left[(1-\gamma)\left(K_{q+t}^{\alpha}\left(A_{L, q+t} L_{q+t}\right)^{1-\alpha}\right)^{(\sigma-1) / \sigma}+\gamma\left(A_{N R, q+t}\left(E_{q+t}+N_{t}\right)\right)^{(\sigma-1) / \sigma}\right]^{\sigma /(\sigma-1)}
\end{aligned}
$$

Data will be used for all parameters and variables only letting the oil extraction and price be endogenously determined by the model. The only parameters which are not available from previous research and public data are the time horizon, the technological improvements in mining and the curvature of the mining cost function. Next, all exogenous parameters and time paths will be declared or calibrated while the procedure for choosing a time horizon will be described in the subsequent subsection.

\subsection{Data and parameter values}

In order to perform this exercise, a number of parameter values and time series are needed. A difficulty here is that while oil prices and scarcity are determined on the world market, many parameter values, most notably on the demand side, are not available on an aggregate global level. To circumvent this problem, the model is calibrated to the US economy and then, based on the US share of world oil consumption, the labor and capital inputs are scaled accordingly. E.g. if the US consumes $50 \%$ of the world supply of oil in a certain year, then the US labor and capital inputs are multiplied by two to get the world economy. The implicit assumption underlying this procedure is that the oil input for a unit of output is the same globally as in the US. ${ }^{25}$

No estimates are available for the oil reserves in 1949. Hence, to get a proxy for this number the oil consumption from 1949-2009 is added to the remaining reserves in 2010 - i.e. a total of $2.56 * 10^{12}$ barrels. ${ }^{26}$ Thus, in the main calibration it is assumed that the reserves reported in 2010 are representative of the true beliefs of the market also in 1949. In the section presenting the results, the calibration outcome of an alternative assumption is briefly discussed. Namely that the beliefs of the stocks in each year is what

\footnotetext{
${ }^{25}$ The US share of world oil consumption starts at around $55 \%$ in 1949 and gradually falls to $22 \%$ in 2009 .

${ }^{26}$ Data from BP's statistical review of world energy from 2011 can be obtained at www.bp.com. Oil consumption data is not available on the US level prior to 1965. To get US oil consumption from 1949 the trend from 1965 onwards is extrapolated backwards. The estimated reserves in 2010 are roughly equal in size to the amount consumed from 1949 to 2009.
} 
was reported in that year. This will make little difference to the main results.

For most parameters and time series, the calibration uses the same values as those used by Hassler et al. (2011). ${ }^{27}$ Using US data on energy consumption, labor, capital and output they calibrate the time series for energy saving technology and the labor and capital augmenting technology. ${ }^{28}$ They also calibrate the elasticity of substitution between energy, on one hand, and capital and labor, on the other, to be close to zero which means production is close to a Leontief specification. Hence, I will use $\sigma=0.05$. It is important to note that Hassler et al.'s calibration is based on the demand side. Therefore, they only need to assume a production function (CES) and the demand structure (perfect competition). Given these they can then get the technology time series and the elasticity of substitution parameter by using observed prices and factor inputs. Hence, they can perform this exercise without specifying whether it is a Hotelling or some other model that determines supply. Since the upcoming calibration uses the same demand side assumptions as Hassler et al, using their time series and parameters is appropriate regardless of whether the aim is to calibrate the infinite or the rolling horizon model. ${ }^{29}$

Using a standard capital to labor ratio, $\alpha$ is set to $30 \%$. The depreciation rate $\delta$ was set to $5 \%$ per year. The subjective discount factor $\beta$ is chosen to 0.95 , i.e. a yearly discount rate of $5 \%$, and a CRRA utility function is used with a risk aversion constant of 1 . The depreciation of capital $(\delta)$ is set to $5 \%$. As $\gamma$ is co-determined with $A_{N R}$ and $A_{L}$ in Hassler et al.'s (2011) paper I will use their value of $\gamma=5 \%$. This also roughly corresponds to energy's share of output in the US.

The three remaining calibration choices pertain to the time horizon, to the amount of alternative energy inputs ( $N$ in equation 17$)$ and the extraction costs. The time horizon is important since it will determine when the shift to the scarcity phase will occur and thus when prices will start to rise. It will be elaborated upon in the next subsection.

The amount of alternative energy inputs is important for two main reasons. Firstly, it determines the total supply of energy and hence whether oil is considered scarce or not which determines the length of the first phase. Secondly, it will affect how hard scarcity of oil will hit the economy when the oil reserves eventually start binding - a smaller amount of alternative energy implies a steeper price increase when scarcity hits. Data for the oil share of energy in the US in each year is taken from the Energy Information Administration. ${ }^{30}$ Thus, $N$ is the remaining share.

The extraction costs need to be calibrated as well. The functional form will be $M_{t}=$

\footnotetext{
${ }^{27}$ The prices, costs, reserves and inputs obtained from other sources were deflated appropriately to match the units from Hassler et al.'s (2011) paper.

${ }^{28}$ Energy consumption from the US Energy Information Administration (EIA), labor from the Bureau of Labor Statistics (BLS) and capital and output from the Bureau of Economic Analysis (BEA).

${ }^{29} \mathrm{~A}$ notable detail is that energy saving technology is assumed to apply equally well to all types of energy since they are perfect substitutes (they apply to both $E$ and $N$ in the model). In Hassler et al.'s (2011) calibration they assume all fossil energy sources to be perfect substitutes and then calibrate the model to the total supply of those. In the calibration in this paper non-oil fossil sources are contained in $N$ together with all other energy sources. As coal and gas constitute the lion share of all non-oil energy sources this assumption should not affect the appropriateness of using Hassler et al.'s estimates here.

${ }^{30}$ Yearly data was used but in general it oscillates around $40 \%$.
} 
$E_{t}^{\theta} / A_{m, t}{ }^{31}$ Three parameter choices need to be made here. Firstly $\theta$, which catches the curvature of costs with respect to the amount extracted in a single year. Secondly $g_{m, t} \equiv\left(A_{m, t+1}-A_{m, t}\right) / A_{m, t}$, which represents how fast the mining technology evolves. Data on these two parameters is not readily available or easily calibrated. For simplicity, I will assume that both of them are constant. The model will be simulated multiple times to see which parameter combination $-\theta$ and $g_{m}$ - that best fits the data and how sensitive the results are to changes in these parameters. As will be shown in the results, the choice of these parameters is not very important. Thirdly, the mining technology level needs to be pinned down. Also this value is scarcely attainable. But, given that we have chosen a value for $\theta$ and $g_{m}$, it is enough to know the average mining costs and the amount extracted in one year to deduce the mining technology level in all other years. Although far from perfect, the best available source for the average mining cost for various regions that I have found comes from a recent online news article by Reuters. ${ }^{32}$ They give estimates of the average extraction costs (operating and capital costs) in the most important oil producing countries. They base their estimates on the International Energy Agency world report from 2008 and on interviews they have conducted with various oil companies. Weighing the average extraction costs by the size of the reserves in that country, the average global extraction cost is set to $12 \$ /$ barrel in $2008 .^{33}$

Finally, since the model's decision maker maximizes over many decades, a simulation of the model also requires input beyond our current date. To get a proxy for these market beliefs, the time series for capital, labour, technologies and alternative energy input were simply extrapolated forward.

\subsection{Choosing the time horizon}

The key parameter when applying the model to the world economy is the time horizon of the oil market. Unfortunately, there is no earlier research to guide us in this choice. The approach here will therefore be to first obtain a prior for the time horizon, using data for reserves and price changes for 56 different resources, and use it when simulating the model. Second, the time horizon will be a free parameter using a standard least squares maximum likelihood estimation (MLE) thereby obtaining a time horizon that best fits the model to the data. The MLE procedure also allows for a horizon which is (practically) infinite.

\footnotetext{
${ }^{31}$ There is a class of models, most generally treated by Farzin (1992), whereby costs go up as one digs deeper. This makes the problem dynamic even when the stock is infinite as more extraction today increases costs tomorrow. Incorporating such spillovers in this paper would make the problem dynamic also in the first phase, generally increasing the price over time. On the other hand costs may fall due to technological development in extraction. The numbers attained in the calibration for oil here thus represent the net of these two effects. Lin \& Wagner (2007) empirically compare the two forces for a number of minerals and show that the two effects have more or less offset each other so that costs have stayed constant.

${ }^{32}$ http://www.reuters.com/article/2009/07/28/oil-cost-factbox-idUSLS12407420090728

${ }^{33}$ E.g. the average cost per barrel was estimated to $4-6 \$$ in Saudi Arabia, $15-30 \$$ in Nigeria and $20 \$$ in Venezuela. Instead looking at the Energy Information Administration's (2011) report on performance profiles of energy producers suggests average extraction costs (or lifting costs) at a slightly lower level of 8-9 \$/barrel.
} 
The rolling horizon model predicts that if the resource stock can be expected to last beyond the market's horizon then there should not be a growth component in the price. In contrast, if stocks can be expected to last for less than the market's horizon then there should be a growth component (see the text leading up to Proposition 1). Therefore, to get a prior guess of the time horizon, essentially the idea is to see for which "remaining years to exhaustion" there seems to be a positive price growth trend for the exhaustible resources in the data. The details of this procedure and results are described in Appendix C. That exercise, which by no means deals with potential problems of reversed causality, suggests 40 years to be a good prior guess for the time horizon before going to the MLE procedure.

The MLE exercise essentially implies running the full simulation once for every time horizon (including an infinite time horizon) and seeing which yields a price path which deviates the least from the data.

It is important to note that whether scarcity plays a role or not will be determined endogenously in every time period. An alternative would be to let the often used reserve to production ratio $(\mathrm{R} / \mathrm{P})$ exogenously determine whether the resource constraint is binding within the owner's horizon. But the $\mathrm{R} / \mathrm{P}$ ratio would be clearly inferior. This is since the resource owner in the model takes growth (in capital, technology and population) into account when planning how much to extract and when making price forecasts while an $\mathrm{R} / \mathrm{P}$ ratio would not. In general, in a growing economy, demand will increase over time. Hence, since the $\mathrm{R} / \mathrm{P}$ ratio assumes oil owners plan to extract at the same rate as today they essentially ignore the increased demand and overestimate the remaining years to exhaustion.

\subsection{Results}

The prior of $T=40$ will be used first, then it will be compared with the outcome of the MLE procedure which backs out the best performing horizon. Finally, the particular alternative of an infinite horizon will be reviewed.

In general the extraction path obtained by the model fits the data quite well. This is largely due to the calibrated choice of near Leontief production which essentially does not leave much freedom in choosing oil consumption to be anything else than what matches the data on capital, labor and technologies. As such, this result is nearly independent of the choice of time horizon. Thus, the real test of the model comes in how well it does in matching the price of oil. In Figure 6 (right), the price path of the model with a 40 year horizon is compared to data. ${ }^{34}$ The best fit is obtained with $\theta=1.1$ and $g_{m}=1.5 \%$. As can be seen, the model's price closely matches the downward sloping price trend in the years before the first oil crisis. It also predicts the sudden change of trend observed in 1998 and follows the sharply increasing prices thereafter. There is a sensitivity analysis of the results in Appendix C. What the model cannot explain is the oil crisis - the sharp

\footnotetext{
${ }^{34}$ The real domestic First Purchase Price for the US is used. Data available at www.eia.gov.
} 

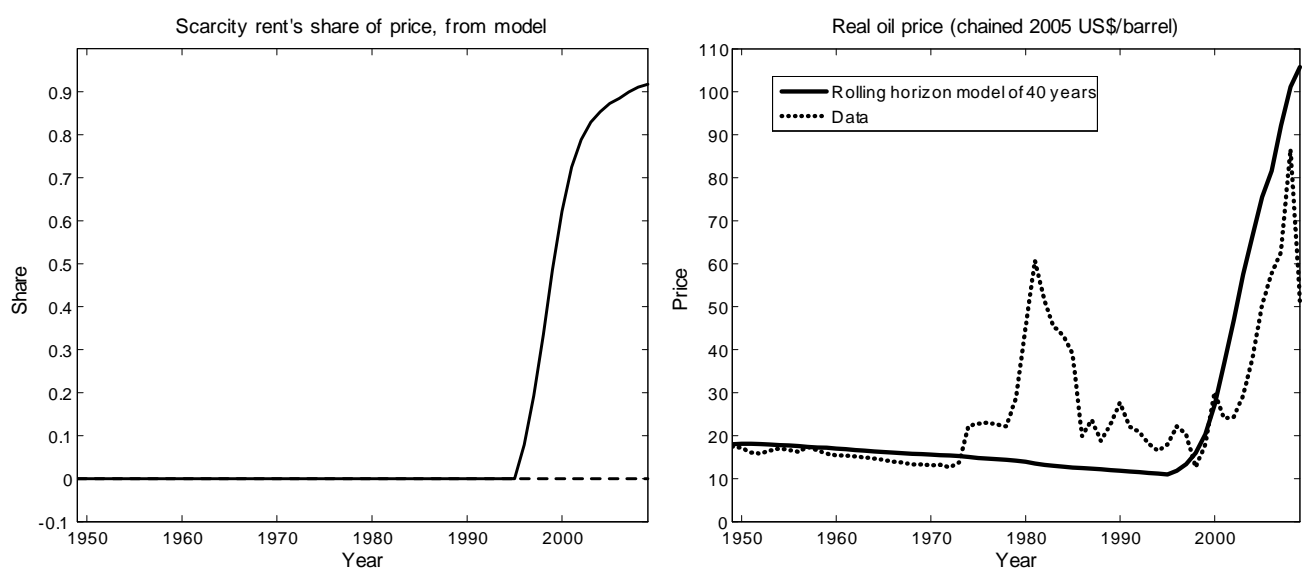

Figure 6: The rolling horizon model calibrated to the oil market. $\theta=1.1, g_{m}=1.5 \%$, $\rho=1$, extraction cost per barrel in $2008=12 \$, T=40$.

price increase in 1972-1981 and the subsequent decrease in 1982-1986. However, although there is an ongoing debate about which the most important reasons for the oil crisis were, there seems to be a consensus that it had little to do with resource scarcity in its long run sense. Rather, a mix of failing price limitations, monopoly power, monetary expansion leading to increased demand, business cycle fluctuations and wars in the Middle East seem to explain these particular historical events (see for example Barsky \& Kilian, 2002; Hamilton, 2003; Barsky \& Kilian, 2004; Kilian, 2009; and references therein). As none of these market imperfections are included in the model of this paper it would indeed be surprising if the model, in the current form, had any predictive power during those years. I will elaborate a bit more on this in the next subsection.

The MLE procedure was used with time horizons from 20 to 70 and with an infinite horizon. ${ }^{35}$ The choice of time horizon mainly affects the timing of the price increase but not the growth rate before. ${ }^{36}$ The MLE was estimated to $T=38$. This is reassuring as it is close to the prior guess of 40 years. For robustness, the residuals were also computed under the freedom of changing the level of the price path. I.e. the whole price path was shift for each simulation to be as close to data as possible on average. This is in order for the qualitative shape to drive the MLE results rather than level effects. The residuals were also computed when leaving out the years of the oil crisis and when extrapolating the data from before and after to get rid of the peak during that period. Roughly the same MLE horizon was obtained with all the alternative procedures, although usually smaller by a few years. For an overview of the results see Figure 9 in Appendix C.

\footnotetext{
${ }^{35}$ In practice all time horizons strictly below 30 years yield identical results. For these horizons the resource constraint is non-binding for the whole period of 1949-2009 and hence the theoretical model predicts that we should observe identical results. On the other side of the spectrum, already 70 years essentially gives the same results as an infinite horizon in this simulation. The important issue in calibrating the infinite horizon model is that the resource constraint is binding already in 1949. The infinite horizon calibration was done using a single finite time problem of 150 years.

${ }^{36}$ Choosing a time horizon of 30 years will roughly delay the break in the price trend by about ten years compared to a 40 year horizon.
} 

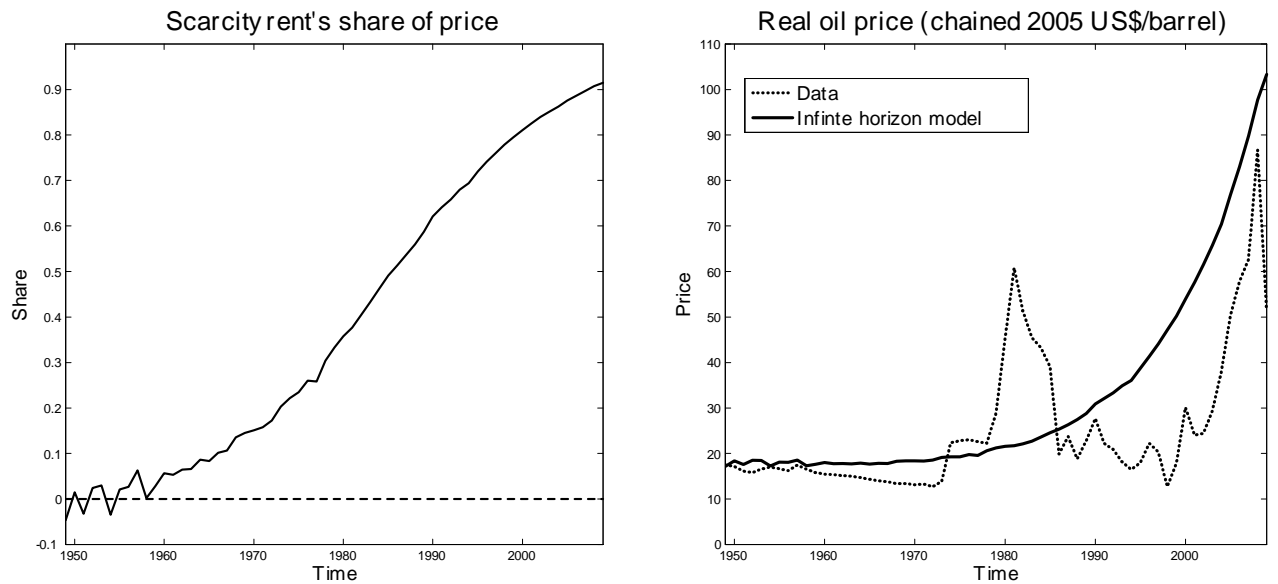

Figure 7: Calibration results of the infinite horizon model. $\theta=1.1, g_{m}=1.5 \%, \rho=1$, extraction cost per barrel in $2008=12 \$$.

An interesting comparison can be made with the infinite horizon model. Simulating such a model and varying the parameters $\theta$ and $g_{m}$ yields a price path which is slowly increasing from about 1960 and onwards (see Figure 7, right). ${ }^{37}$ The infinite horizon model thus predicts that the price increase should happen about 40-45 years too early. For such a story to be reasonable, one would need to believe that the oil crisis was indeed an indication of scarcity and that the U-shape of the oil price in 1981 to 2008 was due to some anomaly. This does not square with the earlier research (presented above) which has shown that the oil crisis itself was the anomaly. To highlight the connection to the second stylized fact in the introduction, also the scarcity rent's share of the price is depicted in Figures 6 and 7. In the infinite horizon model (Figure 7) it starts at around zero but rises steadily from the beginning, while in the rolling horizon model (Figure 6) it is zero until 1998 and rising rapidly thereafter to around 80-90 per cent during the last years of the sample. In this respect the rolling horizon model matches the second and third stylized facts also in terms of timing, while the infinite horizon does not. It may also be interesting to note that, had we assumed the belief of the stock in each year to be the one reported in that year, then the scarcity rent, and hence the price, would have been substantially higher already in the beginning. Meanwhile the qualitative shape of the price path using this alternative assumption would not have replicated data any better.

\subsection{Some considerations outside of the model}

In the calibration of the model, technology and reserves were taken as exogenous from data. This seems like a reasonable starting point when trying to replicate historical price data. However, it seems plausible that both technology and exploration are in reality

\footnotetext{
${ }^{37}$ The best fit with an infinite horizon is obtained with parameters $\theta=0.9$ and $g_{m}=0 \%$. However, the exact value of these turns out to not be very important neither qualitatively nor quantitatively, so the figure shows the simulation with the same $\theta$ and $g_{m}$ parameter values as in the simulation of a rolling horizon of 40 years.
} 
endogenous, so that if prices (within the market's horizon) are expected to rise, then more efforts are devoted to these activities. Including these aspects may have bearing on how the model would predict future prices. For instance, if we take the model at face value, then the oil price is expected to rise from now onwards. However, if endogenous technology and exploration is added it should be possible, by the lumpy nature of these processes, that the perceived scarcity may fall (either due to technology reducing demand for oil or exploration increasing supply) so that the economy goes back to the first phase where the resource constraint is not binding. Although it is beyond the scope of this paper, it is theoretically conceivable that such forces could partly explain why prices first increased during the oil crisis years - due to increased perceived scarcity - and then fell due to perceived scarcity leading to increased technological efforts, as suggested by Hassler et al. (2011), or increased exploration efforts. Likewise, it is conceivable that these forces can partly explain the drop of the oil price in 2009 and its slower increase thereafter. For such a prediction to hold true we should observe some of kind of scarcity driven rents during the rise of the price which then disappear when the price starts falling again.

\section{Concluding discussion}

This paper has shown that a seemingly simple assumption, that of the time horizon of economic agents, has important consequences when modeling exhaustible resources. The initial model is kept as simplistic as possible in order to highlight this point. It also explains the main empirical findings in the resource economics literature: that the long run pattern of resource prices was falling or constant during the 20th century; that the empirical literature does not support an increasing scarcity rent and a positive connection between price growth and the interest rate; and that the prices and profits, of oil in particular, started increasing sharply around the turn of the millennium. Furthermore, the model shows significant predictive power when calibrated to the oil market and proposes that the rising price around the millennium shift was due to scarcity being possible within the market's horizon. The policy implication of this is that, for instance, when designing instruments to reduce $\mathrm{CO} 2$ emissions policy makers should take into account that scarcity may be an important element in determining price in the future, although it has not been so throughout most of the last century.

One question that may arise is how economic agents value keeping reserves past their forecasting horizon. It was shown that attaching a final value to the stock does not by itself alter the main results. Rather, it depends on how this final value changes over time. Furthermore, it was shown that, even though a rolling horizon implies bounded rationality by agents, rolling horizon expectations will be time-consistent when the rule of thumb prescribes a zero final value to the stock - constant prices are both expected and realized. In this case resource owners will not get the opportunity to learn from experience that making finite plans is not optimal.

Generally, macroeconomic models are not qualitatively affected by assuming a rolling 
horizon. For instance, capital accumulation models show similar results with both infinite and rolling horizons - capital accumulates slightly slower with a rolling horizon and converges to a lower steady state. Also a model where agents consume some wealth with which they are initially endowed will have this property. Here, the difference will be that consumption will fall slightly faster within a rolling horizon model as compared to one with an infinite horizon. The outcome of the rolling horizon model will look much like an infinite horizon model with slightly more impatient agents. It may be the case that in earlier evaluations of capital and wealth models, rolling horizon behavior has been confused with impatience since, as far as outcomes go, they are usually hard to tell apart.

A common expectation is that if prices were to rise, a substitute for the resource would be searched for and eventually found. But if the trend and level of the resource price do not reflect the scarcity of the resource, which is the case with rolling horizons, this search will be initiated too late. Scarcity may then become a serious limitation to the economy before a substitute resource or technology has been found. From a welfare perspective, this may be a serious downside of a market using a rolling planning horizon.

\section{Acknowledgements}

I am especially indebted to John Hassler, Torsten Persson and David Weil for many valuable comments. I would also like to thank Klaus Adam, David von Below, John Boyce, Ron Freier, Johan Gars, Bård Harstad, Geoffrey Heal, Lutz Kilian, Paul Klein, Peter Nilsson, Conny Olovsson, Yaniv Reingewertz, Nicholas Sheard, Sjak Smulders, Kjetil Storesletten, Joseph Zeira, Robert Östling and seminar participants at the IIES, Hebrew University, the SURED conference, Bergen School of Economics, Toulouse School of Economics, University of Oslo, BI, ETH, OxCarre, SSB, Umeå University and IFN. Thanks also to Christina Lönnbladh for proof-reading. Funds from Handelsbanken research funds and the Research Council of Norway are acknowledged.

\section{References}

[1] Abgeyebge, T.D. (1989), "Interest Rates and Metal Price Movements: Further Evidence", Journal of Environmental Economics and Management, Vol. 16, Iss. 2, pp. 184-192.

[2] Agnani, B., Gutiérrez, M.J., Iza, A., (2005), "Growth in overlapping generation economies with non-renewable resources", Journal of Environmental Economics and Management, Vol.50, Iss. 2, p.p. 387-407.

[3] Alhajji, A. F., \& Huettner, D. (2000). "OPEC and World Crude Oil Markets from 1973 to 1994: Cartel, Oligopoly, or Competitive?". The Energy Journal, Vol. 21, Iss. $3,31-60$. 
[4] Alquist, R., Kilian, L., and R.J. Vigfusson (2012), "Forecasting the Price of Oil," in G. Elliott and A. Timmermann (eds.), Handbook of Economic Forecasting, 2, Amsterdam: North-Holland.

[5] Arrow, K. \& Chang, S. (1982), "Optimal pricing, use, and exploration of uncertain natural resource stocks" Journal of Environmental Economics and Management, Vol. 9, pp. 1-10.

[6] Barsky, R.B. \& Kilian, L. (2002) "Do we really know that oil caused the great stagflation? A monetary alternative." NBER Macroeconomics Annual 2001, Vol. 16, 137-198.

[7] Barsky, R.B. \& Kilian, L. (2004), "Oil and the Macroeconomy since the 1970s" The Journal of Economic Perspectives, Vol. 18, No. 4 pp. 115-134.

[8] Board of Trustees (2009), Federal Old-Age and Survivors Insurance and Federal Disability Insurance Trust Funds. The 2009 Annual Report of the Board of Trustees of the Federal Old-Age and Survivors Insurance and Federal Disability Insurance Trust Funds.Washington, DC: U.S. Government Printing Office.

[9] Bone, J., Hey, J.D., Suckling,J. (2009). "Do people plan?” Experimental Economics, Vol. 12, pp. 12-25.

[10] Caliendo, F., \& Aadland, D. (2007). "Short-term planning and the life-cycle consumption puzzle." Journal of Economic Dynamics and Control, Vol. 31, Iss. 4, pp.1392-1415.

[11] Carbone, E., Hey, J.D. (2002), "A test of the principle of optimality", Theory and Decision, Vol. 50, pp. 263-281.

[12] Chermak, J. M., Patrick, R. H., 2001. "A microeconometric test of the theory of exhaustible resources". Journal of Environmental Economics and Management Vol. 42, pp.82-103.

[13] Clark, A.R. (1998), "Batch sequencing and sizing with regular varying demand", Production Planning and Control Vol. . 9, No. 3, pp. 260-266

[14] Dasgupta, P. \& Heal, G. (1974) "The Optimal Depletion of Exhaustible Resources", The Review of Economic Studies, Vol. 41, pp. 3-28.

[15] Davidson, P. (1963), "Public policy problems of the domestic crude oil industry", The American Economic Review, Vol. 53, pp. 85-108.

[16] Davison, R. (1978) "Optimal Depletion of an Exhaustible Resource with Research and Development towards an Alternative Technology", The Review of Economic Studies, Vol. 45, No. 2, pp. 355-367. 
[17] Dequech, D. (2001) "Bounded rationality, institutions and uncertainty", Journal of economic issues. Vol. 35, Iss. 4, pp. 911-930.

[18] Dunn, S.P. (2001) "Bounded rationality is not fundamental uncertainty: A Post Keynesian perspective", Journal of Post Keynesian Economics. Vol. 23, Iss. 4, pp. $567-588$.

[19] Easley, D. \& Spulber, D.F., (1981), "Stochastic Equilibrium and Optimality with Rolling Plans", International Economic Review, Vol. 22, No. 1, pp. 79-103.

[20] Ellis, G. M., Halvorsen, R., Aug. 2002. "Estimation of market power in a nonrenewable resource industry". Journal of Political Economy Vol. 110, No. 4, pp. 883-899.

[21] Ellsberg, D. (1961) "Risk, Ambiguity and the Savage Axioms", The Quarterly Journal of Economics, Vol. 74, No. 4, pp. 643-669.

[22] Energy Information Administration (2011), "Performance profiles of major energy producers 2009", US Energy Information Administration, Dept of Energy, Washington DC.

[23] Farzin, Y. H. (1992). "The time path of scarcity rent in the theory of exhaustible resources". The Economic Journal, Vol. 102, No. 413, pp. 813-830.

[24] Findley, T. S., \& Caliendo, F. N. (2009). "Short horizons, time inconsistency, and optimal social security." International Tax and Public Finance, Vol. 16, No. 4, pp. 487-513.

[25] Friedman, M. (1953). Essays in positive economics (Vol. 231). University of Chicago Press.

[26] Friedman, M. \& Savage, L., (1948), "The utility analysis of choices involving risk" The Journal of Political Economy, Vol. 56, No. 4, pp. 279-304.

[27] Fudenberg, D. \& Levine, D.K. (1993), "Self-Confirming Equilibrium", Econometrica, Vol. 61, No. 3, pp. 523-545.

[28] Gabaix, X. (2011). "A sparsity-based model of bounded rationality" (No. w16911). National Bureau of Economic Research.

[29] Gilboa, I., Schmeidler, D. (1989) "Maxmin Expected Utility with Non-Unique Prior", Journal of Mathematical Economics, Vol. 18, pp. 141-153.

[30] Gneezy, U., List, J. \& Wu, G. (2006) "The Uncertainty Effect: When a risky prospect is valued less than its worst possible outcome", The Quarterly Journal of Economics, Vol. 121, pp. 1283-1309.

[31] Goldman, S. M. (1968), "Optimal Growth and Continual Planning Revision", The Review of Economic Studies, Vol. 35, No. 2 pp. 145-154. 
[32] Golosov, M., Hassler, J., Krusell, P., \& Tsyvinski, A. (Forthcoming). "Optimal taxes on fossil fuel in general equilibrium" Econometrica.

[33] Halvorsen, R., Smith, T. R., (1984). "On measuring natural-resource scarcity". Journal of Political Economy Vol. 92, No. 5, 954-964.

[34] Halvorsen, R., Smith, T.R. (1991), "A Test of the Theory of Exhaustible Resources", Quarterly Journal of Economics, Vol. 106, No. 1, pp. 123-140.

[35] Hamilton, J.D. (2003), "What is an oil shock?" Journal of Econometrics, Vol. 113, Iss. 2, pp. 363-398.

[36] Hamilton, J.D. (2009) "Understanding Crude Oil Prices" Energy Journal, Vol. 30, No. 2, pp. 179-206.

[37] Hassler, J., Krusell, P., Olovsson, C., (2011), "Directed Energy-Saving Technical Change", mimeo Stockholm University.

[38] Hart, R., \& Spiro, D. (2011). "The elephant in Hotelling's room". Energy Policy, Vol. 39, No. 12, pp. 7834-7838.

[39] Hartwick, J. M. (1977). "Intergenerational equity and the investing of rents from exhaustible resources." The american economic review, Vol. 67, No. 5, pp. 972-974.

[40] Heal, G., Barrow, M (1980), "The Relationship between Interest Rates and Metal Price Movements", The Review of Economic Studies, Vol. 47, No. 1, pp.161-181.

[41] Heal, G. (1976) "The relationship between price and extraction cost for a resource with a backstop technology", Bell Journal of Economics Vol. 7, pp. 371-378.

[42] Hotelling, H. (1931) "The economics of exhaustible resources", Journal of Political Economy, Vol. 39, pp. 137-175.

[43] Hey, J.D. (2002) "Experimental economics and the theory of decision making under risk and uncertainty." Geneva Papers on Risk and Insurance Theory, Vol. 27, pp. 5-21.

[44] Hey, J.D. , Knoll, J.K. (2007), "How far ahead do people plan?", Economics Letters Vol. 96 , pp. 8-13.

[45] Jéhiel, P. (1995). "Limited horizon forecast in repeated alternate games". Journal of Economic Theory, Vol. 67, No. 2, 497-519.

[46] Johnson, E.J., Camerer, C., Sen, S., Rymon, T. (2002), "Detecting Failures of Backward Induction: Monitoring Information Search in Sequential Bargaining", Journal of Economic Theory Vol. 104, pp. 16-47. 
[47] Kaganovich, M., (1985), "Efficiency of Sliding Plans in a Linear Model with TimeDependent Technology", Review of Economic Studies Vol. 52, No. 4, pp. 691-702.

[48] Kamien M.I., Schwartz N.L. (1978) "Optimal Exhaustible Resource Depletion with Endogenous Technical Change", The Review of Economic Studies, Vol. 45, No. 1, pp. 179-196.

[49] Kilian, L. (2009), "Not All Oil Price Shocks Are Alike: Disentangling Demand and Supply Shocks in the Crude Oil Market", American Economic Review Vol. 99, No. 3, pp. 1053-1069.

[50] Kilian, L., \& Hicks, B. (2012). "Did unexpectedly strong economic growth cause the oil price shock of 2003-2008?". Journal of Forecasting. Vol. 32, No. 5, pp. 385-394.

[51] Knight, F.H. (1921) "Risk, Uncertainty, and Profit", Boston, MA: Hart, Schaffner \& Marx; Houghton Mifflin Company.

[52] Krusell, P. \& Smith, A.A.Jr. (2003), "Consumption-savings decisions with quasigeometric discounting" Econometrica, Vol. 71, No. 1, pp. 365-375.

[53] Lin, C.-Y. \& Wagner, G., (2007), "Steady-state growth in a Hotelling model of resource extraction", Journal of Environmental Economics and Management Vol. 54 , p.p. $68-83$.

[54] Liski, M., \& Tahvonen, O. (2004). "Can carbon tax eat OPEC's rents?". Journal of Environmental Economics and Management, Vol. 47, No. 1, pp. 1-12.

[55] Okullo, S.J., Reynes, F. (2012). "Imperfect cartelization in OPEC". Available at SSRN.

[56] Perea-López, E., Ydstie, B.E. \& Grossmann, I.G. (2003), "A model predictive control strategy for supply chain optimization", Computers and Chemical Engineering, Vol. 27, pp. $1201-1218$.

[57] Polasky, S. (1992). "Do oil producers act as "oil"igopolists?" Journal of Environmental Economics and Management, Vol. 23, No. 3, pp. 216-247.

[58] Simon, J. L. (1996) The ultimate resource 2, Princeton University Press, Princeton, New Jersey.

[59] Spiro, D. (2012). Resource Prices and Planning Horizons. Available at SSRN 2155725.

[60] Solow R.M. and Wan F.Y. (1976) "Extraction Costs in the Theory of Exhaustible Resources", The Bell Journal of Economics, Vol. 7, No. 2, pp. 359-370.

[61] Smulders, S., \& De Nooij, M. (2003). "The impact of energy conservation on technology and economic growth". Resource and Energy Economics, Vol. 25, No. 1, pp. 59-79. 
[62] Spulber, D. F. (1991). "Economic Planning with Rolling Horizons". Theoretical Foundations of Development Planning: Development policy and the planning process, pt. A, 1,417 .

[63] Tahvonen,O. and Salo, S. (2001) "Economic growth and transitions between renewable and nonrenewable resources", European Economic Review, Vol. 45, pp.13791398 .

[64] Van der Ploeg, F., \& Withagen, C. (2012). "Is there really a Green Paradox?". Journal of Environmental Economics and Management.Vol. 64, Iss. 3, pp. 342-363.

[65] van Veldhuizen, R. \& Sonnemans, J. (2011), "Nonrenewable Resources, Strategic Behavior and the Hotelling Rule: An Experiment", Tinbergen Institute Discussion Paper, TI 2011-014/1.

[66] Weinstein, M.C., and Zeckhauser, R.J. (1975) "The optimal consumption of depletable natural resources", The Quarterly Journal of Economics, Vol. 89, No. 3, pp. 371-392.

\section{Appendix A - Further discussion of rolling horizons (On- line)}

\subsection{A formal description}

For each $q \in[0, \infty)$ the representative agent forms a plan of length $T$ and executes its first period. Let $C$ denote the control variable of consumption and $X$ a possibly singular set of state variables. Moreover, let $q$ denote the date at which the plan is formulated, let $t$ denote the number of time periods from the planning date $q$ and finally $T$ denote the length of the plan. A plan formulated at $q$ is then a set $\left[C_{q+t}^{*}, \mathbf{X}_{q+t+1}^{*}\right]_{t=0}^{T}$ that satisfies $\max \sum_{0}^{T} \beta^{t} U\left(C_{q+t}\right)$ subject to $\mathbf{X}_{q+t+1}=\mathbf{X}_{q+t+1}\left(C_{q+t}, \mathbf{X}_{q+t}\right)$, the initial condition $\mathbf{X}_{q}$ and appropriate terminal conditions applied to $\mathbf{X}_{q+T}$. The actual outcome is then a set $\left[\tilde{C}_{q}, \tilde{\mathbf{X}}_{q}\right]_{q=0}^{\infty}$, i.e. a sequential implementation of the first period of each plan.

\subsection{Experimental evidence}

Shortsightedness and underestimation of future values has support in experimental research. Hey \& Knoll (2007) show that many people do not plan ahead even when the intertemporal problem is simple to solve. Instead, they maximize their current payoff and attribute no value to future outcomes (Hey \& Knoll, 2007; Bone et al., 2009). Regarding the time inconsistency problem, this research shows that people are unable to predict their own behavior (Hey, 2002) and that they themselves do not assume that their own future behavior will be rational (Carbone \& Hey, 2002). Moreover, the ability to backward 
induct properly is limited (Johnson et al., 2002) and the subjects in these experiments do not necessarily learn from experience (Bone et al., 2009).

\subsection{Possible behavioral explanations}

Do agents really have full information up until a certain point in time and then no information beyond? This is obviously a simplification. This section will discuss behavioral mechanisms pointing towards a rolling horizon and roughly sketch a few more elaborate ways of modeling it. However, the simplification made in this paper carries no obvious bias, since the driving mechanism is that the plan is finite and not whether there is some uncertainty within the plan.

This said, it may be more realistic to have uncertainty gradually increasing with time but going to infinity within finite time. Another alternative mechanism is to have agents ignore all outcomes with a low enough probability to endogenize rolling horizons.

A further option is the concept of ambiguity aversion which also points towards agents using rolling horizons. It has been shown that people generally avoid gambling on, and assign low values to, lotteries where they cannot assess the probability distribution (e.g. Ellsberg, 1961; Gilboa \& Schmeidler, 1989). In a rolling horizon context, this corresponds to preferring to use the assets in the near future, where the outcomes are either known or can be assessed by probabilities, than to use them in the far future where one does not have the information to even form expectations. This is at least numerically easily verified in a simple two-period model of resource extraction with ambiguity aversion, fearing that a backstop will make the resource worthless. If the probability distribution of the backstop appearing is unknown, the resource owner will want to leave no resources for later.

Related to this is a study by Gneezy et al. (2006). They show that the certainty equivalence of a lottery can be lower than the worst outcome of that same lottery. In a rolling horizon setting, this would be equivalent to believing that the continuation value of the asset is negative.

Another possible explanation for a finite horizon may be that finding and processing information is costly. When working on forecasts, at some point an agent has to decide to stop looking further into the future and how to treat the unknown beyond. One could possibly model the additional gains from information and compare them to the costs.

If, instead, one were to assume that agents do not at all care about the utility in the very long run but are not constrained by information, the natural resource results of rolling horizons collapse. This is due to the fact that these agents do care about the price of their assets tomorrow which, in itself, is determined by the price the day after and so on (see Agnani et al., 2005). In this way, the outcomes of the infinite future unfold back to today even though today's agents may not directly care about this. Thus, the distinction in rolling horizons is of agents being myopic due to lack of information rather than lack of care. 
On a theoretical basis, one may well point out the time inconsistency in a person having a plan that (s)he knows might change tomorrow. The question is then why the change is not made already today. But, it would indeed be impossible to know how the plan will be updated tomorrow if one does not have tomorrow's information already today. For a discussion on this, see Dequech (2001) or Dunn (2001). The notion of rationality mostly used in economics works well in the setting of decision making under risk, meaning that agents know the possible outcomes and can assign probabilities to them, as described by Friedman \& Savage (1948). However, if economic decisions need to be made under Knightian uncertainty (Knight, 1921), i.e. without knowing the outcome space and/or the probability distribution, the standard notion of rationality is hardly applicable. In addition, the rolling horizon resource model is dynamically consistent, as is shown in this paper, making rolling horizons a fairly accurate rule of thumb for most, also in hindsight.

\section{Appendix B - Analytical results (Possibly Online)}

\subsection{Proof of Lemma 1}

Rewriting the problem in a more convenient form and (w.l.o.g.) dropping the subscript $q$.

$$
\begin{aligned}
& \max _{\left\{E_{t}\right\}_{t=0}^{T}} \sum_{t=0}^{T} \frac{1}{R^{t}}\left[p_{t} E_{t}-M\left(E_{t}\right)\right] \\
& \text { s.t. } \sum_{t=0}^{\tau} E_{t} \leq S_{0} \text { for all } \tau \leq T .
\end{aligned}
$$

Following the Kuhn-Tucker approach this problem can be rewritten with equalities by introducing the slack variable $\mu=\sqrt{S_{T+1}}$ which yields the Lagrangian:

$$
L=\sum_{t=0}^{T} \frac{1}{R^{t}}\left[p_{t} E_{t}-M\left(E_{t}\right)\right]+\lambda\left[S_{0}-\mu^{2}-\sum_{t=0}^{\tau} E_{t}\right]
$$

Since the objective function is concave the necessary and sufficient conditions for optimality are

$$
\begin{aligned}
\partial L / \partial E_{t} & =0 \leftrightarrow \lambda R^{t}=P_{t}-M^{\prime}\left(E_{t}\right) \\
\partial L / \partial \lambda & =0 \leftrightarrow S_{0}-\mu^{2}-\sum_{t=0}^{\tau} E_{t}=0 \\
\partial L / \partial \mu & =0 \leftrightarrow 2 \lambda \mu=0 .
\end{aligned}
$$

Since $\lambda$ is independent of time the last expression yields two cases.

1. $\boldsymbol{\lambda}=\mathbf{0}$ and $\boldsymbol{\mu} \geq \mathbf{0}$ : The first optimality condition and $p=F^{\prime}$ implies $F^{\prime}\left(E_{t}\right)=$ $M^{\prime}\left(E_{t}\right)$ which gives $E_{t}=E_{\max }$ (by the definition in equation 13). This gives total 
extraction at the final period $T E_{\max }$. Furthermore, $\mu \geq 0$ iff $S_{T+1} \geq 0$ which, by the second condition, holds iff $0 \leq S_{T+1}=S_{0}-T E_{\max }$. Hence, iff $S_{0} \geq T E_{\max }$ then $E_{t}=E_{\max }$ and $p=M^{\prime}\left(E_{\max }\right)$. This concludes the first iff statement in the lemma. $\rightarrow$

2. $\boldsymbol{\lambda}>\mathbf{0}$ and $\boldsymbol{\mu}=\mathbf{0}$ : Using $\lambda>0$ in the first optimality condition in two adjacent periods gives equation (16). $\lambda>0$ and perfect competition (equation 14) gives $F^{\prime}\left(E_{t}\right)>M^{\prime}\left(E_{t}\right)$. Furthemore, equation (16), convexity of $M$ and concavity of $F$ imply $E_{t+1}<E_{t}<E_{\max }$ and $p_{t+1}>p_{t}>M^{\prime}\left(E_{\max }\right)$ for all $t<T-1$. Furthermore, $\mu=0$ iff $0=S_{T+1}=S_{0}-\sum_{t=0}^{T} E_{t}$. Then, since $E_{t}<E_{\max }, \mu=0$ holds only if $S_{0}<T E_{\max }$. Finally, since the two cases $(\boldsymbol{\lambda}=\mathbf{0}$ and $\boldsymbol{\lambda}>\mathbf{0})$ are exhaustive and case 1 holds iff $S_{0} \geq T E_{\max }$ it must be that case 2 holds if $S_{0}<T E_{\max }$ which concludes the second iff statement.

\subsection{Proof of Proposition 1}

Let $x$ denote a planned variable and let $\tilde{x}$ denote a realized variable. The rolling horizon implies a sequence of finite plans where the control variable of the first period of each plan will be realized. To get the sequence of realized variables we solve each plan separately. By Lemma 1 we know $E_{q+t}=E_{\max }$ if $\tilde{S}_{q} \geq T E_{\max }$. In particular, since the rolling horizon owner implements the first period of the plan, then $\tilde{E}_{q}=E_{\max }$. This implies the realized stock according to $\tilde{S}_{q}=\tilde{S}_{0}-q E_{\max }$ until $\tilde{S}_{q}<T E_{\max }$. Let $\bar{q}$ denote the largest natural number such that $\tilde{S}_{0}-\bar{q} E_{\max } \geq T E_{\max }$. Solving we get $\bar{q}=\left\lfloor\frac{\tilde{S}_{0}-T E_{\max }}{E_{\max }}\right\rfloor$. That means $\tilde{E}_{q}=E_{\max }$ and thus that $\tilde{p}_{q}=M^{\prime}\left(E_{\max }\right)$ for $\bar{q}=\left\lfloor\frac{\tilde{S}_{0}-T E_{\max }}{E_{\max }}\right\rfloor$ consecutive periods. This proves part 1 .

$\tilde{p}_{q}=M^{\prime}\left(E_{\max }\right)$ is independent of $R$ and so are the intratemporal profits which, in equilibrium are $\tilde{\pi}=E_{\max } M^{\prime}\left(E_{\max }\right)-M\left(E_{\max }\right)$. To show that the profits are positive we can note that, by the assumptions made on the extraction costs, by $\tilde{\pi}(0)=0$ and by the equilibrium expression of the profits having the property $\tilde{\pi}^{\prime}(\tilde{E})=\tilde{E} M^{\prime \prime}(\tilde{E})+$ $M^{\prime}(\tilde{E})-M^{\prime}(\tilde{E})=\tilde{E} M^{\prime \prime}(\tilde{E})>0$ for all $\tilde{E} \geq 0$ it must be that $\tilde{\pi}(\tilde{E})>0$ for all $\tilde{E}>0$ and in particular $\tilde{\pi}\left(E_{\max }\right)>0$ which concludes the proof of part 2.

At the time period $q=\left\lfloor\frac{S_{0}-T E_{\max }}{E \max }+1\right\rfloor$ then $\tilde{S}_{q}<T E_{\max }$. Since the resource constraint is binding in this case, an increase in $\tilde{S}_{q}$ implies an increase in the planned $E$ in at least some period between $q$ and $q+T$. By equation (16) then follows that the planned $E$ must increase in all periods between $q$ and $q+T$ and, in particular, in the period $q$ itself. The plan for time $q$ is also the outcome in that period. Hence $\frac{d \tilde{E}_{q}}{d S_{q}}>0$. The realized law of motion is $\tilde{S}_{q}=\tilde{S}_{q-1}-\tilde{E}_{q-1}$ implying the stock is decreasing with $q$. This gives, with $\frac{d \tilde{E}_{q}}{d S_{q}}>0$, that the realized extraction is decreasing over time. The price is increasing iff $\frac{d \tilde{p}_{q}}{d \tilde{S}_{q}}=\frac{d \tilde{p}_{q}}{d \tilde{E}_{q}} \frac{d \tilde{E}_{q}}{d \tilde{S}_{q}}<0$. By concavity of $F \frac{d \tilde{p}_{q}}{d \tilde{E}_{q}}<0$. Hence, since we already established realized extraction is decreasing over time, the realized price must be increasing over time. 
The profits per unit are given by $\tilde{\pi}(\tilde{E}) / \tilde{E}=\frac{p(\tilde{E}) \tilde{E}-M(\tilde{E})}{\tilde{E}}=p(\tilde{E})-\frac{M(\tilde{E})}{\tilde{E}}$. Differentiating this w.r.t. $\tilde{E}$ we get $\frac{d \tilde{\tilde{E}}}{d \tilde{E}}=p^{\prime}(\tilde{E})-\frac{M^{\prime}(\tilde{E}) \tilde{E}-M(\tilde{E})}{\tilde{E}^{2}}=p^{\prime}(\tilde{E})-\frac{\tilde{\pi}}{\tilde{E}^{2}}$ in equilibrium. By concavity of $F$ the first element is negative and it was shown earlier in the proof that $\pi$ is positive, hence the whole expression is negative. Since realized extraction is decreasing over time realized per unit profits are then increasing over time. This concludes the proof of part 3 .

\subsection{Proof of Proposition 2}

This proof requires some additional and partly busier notation than what has been used in the body of the paper. Here, a subscript letter denotes the time period at which the plan or forecast is made and the letter within parenthesis is the time period that the plan or forecast regards. For instance, $p_{q}(q+\tau)$ is a forecast made at time $q$ about the price at time $q+\tau$. As before, $\tilde{x}$ is the realized outcome of $x$. For conservation of space the following proof will be displayed using a social planner framework. It is easily verified that a perfect competition setting and a social planner setting yield identical results in a resource problem in both infinite and finite time. Hence, the following results regarding immunity to learning are generalizable to a competitive setting.

Definition 1 An equilibrium is said to be immune to learning for $\chi$ time periods if plans are such that:

1. All planned control variables, $Y_{q}(\tau)$, equal the realized control variables, $\tilde{Y}_{\tau}(\tau)$, for all $q \in\{0, \ldots, \chi-1\}$ and $\tau \in\{q, \ldots, \chi\}{ }^{38}$

2. All planned state variables, $X_{q}(\tau)$ equal the realized state variables, $\tilde{X}_{\tau}(\tau)$, for all $q \in\{0, \ldots, \chi-1\}$ and $\tau \in\{q, \ldots, \chi\}$.

Definition 2 If $\chi<1$ then the equilibrium is said to be not immune to learning.

The following proves part 1 of the proposition.

From Proposition 1 we know that the forecast extraction and price is constant in the first phase and equal to the extraction and price in the first period. That is $E_{0}(\tau)=$ $\tilde{E}_{0}(0)=E_{\max } \forall \tau \in[0, T]$. A period later a new plan is made. Given that the resource constraint is not binding this plan and prognosis will be that extraction is constant and equal to the realized extraction in the first period: $E_{1}(1)=\tilde{E}_{1}(1)=E_{\max }$. This reasoning can be reapplied for later periods. That is, $E_{\chi}(\chi)=\tilde{E}_{\chi}(\chi)=E_{\max }$ for all $\chi$ where the resource constraint is not binding. That is, $\chi=\left\lfloor\frac{S_{0}-T E_{\max }}{E \max }\right\rfloor$. This implies that $E_{q}(\tau)=\tilde{E}_{\tau}(\tau)$ for all $q \in\{0, \ldots, \chi-1\}$ and $\tau \in\{q, \ldots, \chi\}$. A similar argument, now

\footnotetext{
${ }^{38}$ Note that if $\chi>T$ then e.g. $X_{0}(\tau)$ is only defined for $\tau \leq T$ since the plan at time zero does not incorporate outcomes beyond $T$. For immunity to learning in such cases the plan in the early periods only need to be realized in their entirety and no requirement is made about realizations of outcomes beyond what is planned in those early periods.
} 
using $S_{q}(\tau)=\tilde{S}_{q}-(\tau-q) E_{\max }$ as long the stock is not binding, can be applied to the stock which is the only state variable.

The following proves part 2 of the proposition.

To show that there is no immunity to learning it is sufficient to show that some planned control variable is not equal to its realization. Consider the following problems differing only in $T_{1}>T_{2}$ :

1.

$$
\begin{aligned}
& \max \sum_{t=0}^{T_{1}} \beta^{t} U\left(C_{q}(q+t)\right) \\
C_{q}(q+t)= & F\left(E_{q}(q+t)\right)-M\left(E_{q}(q+t)\right), \\
S_{q}(q+t+1)= & S_{q}(q+t)-E_{q}(q+t) \quad S_{q}(q+t+1) \geq 0 \quad S_{q}(q) \text { given }
\end{aligned}
$$

2.

$$
\begin{aligned}
& \max \sum_{t=0}^{T_{2}} \beta^{t} U\left(C_{q}(q+t)\right) \\
C_{q}(q+t)= & F\left(E_{q}(q+t)\right)-M\left(E_{q}(q+t)\right), \\
S_{q}(q+t+1)= & S_{q}(q+t)-E_{q}(q+t) \quad S_{q}(q+t+1) \geq 0 \quad S_{q} \quad(q) \text { given }
\end{aligned}
$$

The following Lemma essentially says that extraction will be lower in all periods in problem 1 compared to problem 2 . This can be verified with any textbook in resource economics and will hence not be proven here.

Lemma 2 Consider problems 1 and 2. Let functions, parameters and initial condition be identical except for $T_{1}>T_{2}$. Then, provided that $S_{q+t+1} \geq 0$ is binding in at least problem $1, E_{q+t}$ of problem 1 is strictly smaller than $E_{q+t}$ of problem 2 for all $t<T_{2}$.

Now consider problem 1. It is also well known that the solution to such a one shot finite horizon exhaustible resource problem is time consistent. Since this problem is identical to a single rolling horizon plan it implies that a rolling horizon plan is internally time consistent. That is, if it, hypothetically, would be carried out in its entirety it would be time consistent. This implies the following:

Lemma 3 Consider a problem starting at $q=q_{1}$ with initial condition $S_{q_{1}}\left(q_{1}\right)$ and another problem staring at $q_{2}=q_{1}+1$ with initial condition $S_{q_{2}}\left(q_{2}\right)$ such that $S_{q_{2}}\left(q_{2}\right)=$ $S_{q_{1}}\left(q_{1}\right)-\tilde{E}_{q_{1}}\left(q_{1}\right)$. Assume that otherwise the problems are identical. Let $E_{q_{1}}\left(q_{1}+1\right)$ denote the planned extraction at time $q_{1}+1$ in the first problem and $E_{q_{2}}\left(q_{1}+1\right)$ denote the planned extraction at $q_{1}+1$ in the second problem. Then $E_{q_{1}}\left(q_{1}+1\right)=\tilde{E}_{q_{2}}\left(q_{1}+1\right)$ iff $T_{2}=T_{1}-1$.

Proof. If $T_{2}=T_{1}-1$ then the second problem in this Lemma is identical to the continuation of the first problem of the Lemma after one period has elapsed. By time consistency 
of the first problem then follows that $E_{q_{1}}\left(q_{1}+1\right)=\tilde{E}_{q_{2}}\left(q_{1}+1\right)$. If $T_{2} \neq T_{1}-1$ then the continuation of the first problem after one period has the same functional forms, parameters and initial conditions as the second problem but the length over which to maximize differs. By Lemma 2 we then know $E_{q_{1}}\left(q_{1}+1\right) \neq \tilde{E}_{q_{2}}\left(q_{1}+1\right)$.

With a rolling horizon, $S_{q+1}(q+1)=\tilde{S}_{q}(q+1)$, so the setting is identical to Lemma 3 , but $T_{2}=T_{1}>T_{1}-1$ which, by Lemma 3 , means $E_{q}(q+1) \neq \tilde{E}_{q+1}(q+1)$ and no immunity to learning. 


\section{Appendix C - Calibration details and results (Online)}

\subsection{Further empirical predictions}

In preparation for the empirical exercise of getting a prior guess for the time horizon on the oil market, this section will formally outline some additional results that contrast the infinite and rolling horizon models. The upcoming results will illustrate how price growth is affected by the estimated size of the remaining stock $(S)$ under each of the horizon assumptions. They follow more or less directly from the analysis of the basic model in Section 3. Starting with an infinite horizon, we have the following result.

Proposition 3 In an infinite horizon model, $\frac{d p_{q}}{d S_{q}}<0$.

Proof. $\frac{d p_{q}}{d S_{q}}=\frac{d p_{q}}{d E_{q}} \frac{d E_{q}}{d S_{q}}$. From the concavity of $F$, it follows that $\frac{d p_{q}}{d E_{q}}<0$. An increase in $S_{q}$ implies an increase in $E$ in at least one period. By equation (7) follows that $E$ must increase in all periods and, in particular, in the first period. Hence $\frac{d E_{q}}{d S_{q}}>0$. The result then follows.

The proposition states a well known result. Namely that today's stock estimates determine the current price so that the lower the estimated stock the higher the price. Hence, as we compare stock estimates in two periods, the period with the highest stock should have the lowest price. Then, in the absence of reserve revisions, as the stock decreases due to extraction, the price will increase when the market has an infinite time horizon. It essentially just reformulates the standard Hotelling (1931) result that there should be a growth component in the price. The prediction that $d p_{q} / d S_{q}<0$ is independent of how long the stock is expected to last.

The previous proposition is contrasted by the model with a rolling planning horizon. Let $\tilde{x}$ denote a realized (as opposed to a planned) variable.

Proposition 4 In a rolling horizon model,
1. $\frac{d \tilde{p}_{q}}{d \tilde{S}_{q}}=0$ if $\tilde{S}_{q}>T E_{\max }$
2. $\frac{d \tilde{p}_{q}}{d \tilde{S}_{q}}<0$ if $\tilde{S}_{q}<T E_{\max }$.

Proof. The first part follows from part 1 of Proposition 1 which implies that $\tilde{p}_{q}=$ $M\left(E_{\max }\right)$ is independent of the stock when $\tilde{S}_{q}>T E_{\max }$. The second part holds iff $\frac{d \tilde{p}_{q}}{d \tilde{S}_{q}}=$ $\frac{d \tilde{p}_{q}}{d \tilde{E}_{q}} \frac{d \tilde{E}_{q}}{d \tilde{S}_{q}}<0$. From concavity of $F$ follows that $\frac{d \tilde{p}_{q}}{d \tilde{E}_{q}}<0$. Since the resource constraint is binding in this case, an increase in $\tilde{S}_{q}$ implies an increase in the planned $E$ in at least some period between $q$ and $q+T$. By equation (16) then follows that the planned $E$ must increase in all periods between $q$ and $q+T$ and, in particular, in the period $q$ itself. The plan for time $q$ is also the outcome in that period. Hence $\frac{d \tilde{E}_{q}}{d S_{q}}>0$. The result then follows. 
The proposition states how the price in a certain time period is affected by the stock size in that time period. Since, in absence of major revisions of the stock size, the stock should be smaller following extraction, it predicts how the price should evolve over time. Following the proposition, the rolling horizon model predicts that as the stock falls this will not affect the price, if the resource constraint is not binding within the market's horizon. On the other hand, if the resource constraint is binding within the market's horizon, falling stocks due to extraction will increase the price. ${ }^{39}$ The main distinction to the infinite horizon is that now the price should contain a growth component conditional on exhaustion being possible within the market's horizon.

\subsection{Data}

Data over remaining reserves has been collected from the US geological survey (USGS) for each year in 1996-2011. ${ }^{40}$ They publish a yearly mineral commodities summary which reports the remaining "Reserve base" and "Reserves" for roughly 80 commodities. In their reports, the reserve base is defined as "...encompassing those parts of the resources that have a reasonable potential for becoming economically available within planning horizons beyond those that assume proven technology and current economics". Reserves are defined as "that part of the reserve base which could be economically extracted or produced at the time of determination". Thus, the estimation of the reserves is a subset of the reserve base. ${ }^{41}$ After excluding some resources where data is lacking and some where the reserves are sufficient for any conceivable time horizon (like stone, sand and salt) a dataset of 54 commodities was constructed. Reserve data was then added for oil and gas which goes back to 1980, i.e. a total of 56 commodities. ${ }^{42}$ Extraction and price data for these commodities was also collected from the USGS and BP. A summary statistics can be found in Table 1 . Note that the $\mathrm{R} / \mathrm{P}$ ratio is presented only for descriptive purposes, it will not be used in the actual empirical exercise.

The predictions from the rolling horizon model depend on whether the resource constraint is binding within the market's time horizon (and this horizon is in fact what this exercise will attempt to back out). In order to know whether this is the case for a specific observation, a measure of the remaining years to exhaustion is needed. Denote by $\tau_{i, q}$ the remaining years to exhaustion of commodity $i$ in year $q . \tau_{i, q}$ should optimally be based on the production prognosis made at year $q$ for the specific commodity. Since actual market forecasts are not consistently available, $\tau_{i, q}$ needs to be proxied in some way. The

\footnotetext{
${ }^{39}$ Here a decrease in the estimated reserves may have a different effect than an increase. If we are in a phase where the resource constraint is non-binding, a drop in reserves may cause the constraint to start binding and hence the price should increase. On the other hand, an increase in reserves (following unexpected "good" news) at the point where the resource constraint is not binding, should not have an effect on the price. This is why both parts 1 and 2 of the proposition are defined with strict inequalities - the derivative at $\tilde{S}_{q}=T E_{\max }$ is not continuous.

${ }^{40}$ See www.usgs.gov.

${ }^{41}$ It should be noted that both terms are engineering based so the label of "economically extracted" should be interpreted as "profitable to extract" rather than "profit maximizing to extract".

${ }^{42} \mathrm{Oil}$ and gas data was taken from BP's Statistical review of World Energy in 2011. See www.bp.com.
} 
Table 1: Summary statistics, 502 obs

\begin{tabular}{|l|l|l|l|l|l|}
\hline & $\min$ & $\max$ & mean & median & std \\
\hline $\mathrm{R} / \mathrm{P}$ & 4 (Indium) & cutoff at 200 & 52.8 & 40 & 43 \\
\hline$\frac{S_{q}}{S_{q-1}}$ & 0.38 (Mercury, 2006) & 4.9 (Graphite, 2002) & 1.037 & 0 & 0.28 \\
\hline$\frac{p_{q}}{p_{q-1}}$ & 0.16 (Tantalum,2000) & 6.25 (Tantalum,1999) & 1.074 & 0.982 & 0.42 \\
\hline$\frac{p_{q, \text { comp }}}{p_{q-1, \text { comp }}}$ & $0.63(2008)$ & $1.19(1993)$ & 1.0035 & 0.985 & 0.14 \\
\hline
\end{tabular}

method here will be to, for each $q$ and $i$, make a production prognosis and compare it to the known reserves at that same time period $\left(S_{i, q}\right)$. For this purpose, the production trend from the years preceding $q$ was extrapolated forward. The method was to use the previous 15 years and give more weight to recent years when calculating the trend.

\subsection{Remaining years to exhaustion and price growth}

The motivation for the upcoming exercise is to obtain a first rough guess of the time horizon for calibrating the model to the oil market in Section 4. It will simply test for which remaining years to exhaustion there possibly is a growth component in the price. It should be emphasized that the exercise contains no exogenous variation for causal identification. So it gives us no guidance on the issue of causality - it is simply descriptive for which remaining years to exhaustion the price contains a growth component. ${ }^{43}$

When no unexpected changes to the reserve estimates occur the stock should fall simply due to extraction. Proposition 4 then predicts that the price growth should have no component of increasing scarcity if $\tau_{q, i}>T$. Thus, if rolling horizons is a correct assumption then, holding other things equal, there should be an additional component in the price growth when we come closer to exhaustion than the market's horizon. It is represented by the coefficient $a_{2}$ in the following regression.

$$
\log \left(\frac{p_{q+t, i}}{p_{q, i}}\right)=a_{1}+a_{2}\left\{\tau_{q, i} \leq T\right\}+b_{2} \log \left(\frac{p_{q+t, a l l}}{p_{q, a l l}}\right)+\varepsilon_{q, i}
$$

The dependent variable $\log \left(\frac{p_{q+t, i}}{p_{q, i}}\right)$ is simply the growth rate of the price in the years following the observation. $b_{2}$ represents the effect of growth in the commodity price index and is meant to deal with business cycle driven price growth. ${ }^{44}$ The regression was run once for each cutoff $T \in[10,80]$. Since this procedure is about the long run growth, average growth over eight years was used (i.e. $t=8$ ). This implies that roughly half of all

\footnotetext{
${ }^{43}$ An earlier version of the paper (Spiro, 2012) included an exercise which deals slightly better with endogeneity issues. That exercise examined how the price changes due to large reserve revisions (interpreted as unexpected news). It rejects an infinite horizon and suggests a horizon of 25 years. However, that exercise precludes larger resources since large revisions hardly occur for them in the data making it less representative of oil.

${ }^{44}$ The central variable for price growth in the previous periods is omitted here as it would pick up the constant effect of remaining years on price growth rendering the exercise meaningless.
} 
stock observations fall out as no data is available for prices after 2010. Again, it should be emphasized that this will not be a test of rivaling horizon assumptions but rather a way of getting a first guess of the time horizon. Also in an infinite horizon model we should expect resources with fewer remaining years of the stock to grow faster than those with many remaining years. One possible concern could be that mining technology has improved over time making prices fall also when the stock is binding within the market's perspective. But if prices systematically change in some direction due to improved mining technology or by deeper mines increasing the costs, this should be picked up by including the price index in the regression. Here we are only interested in the additional growth component when resource scarcity is within the market's horizon. Furthermore, to isolate the effect of falling stocks due to extraction from that of increases or decreases due to news, all observations where large revisions occur $(> \pm 10 \%)$ were excluded.

The results are presented in Figure 8. Looking at the left hand side schedules the coefficient $a_{2}$ obtains its largest value, has the lowest p-value and the residuals are minimized at $T=40 .{ }^{45}$ The right hand side schedule shows the observations and the average yearly growth rate when grouping observations of similar remaining years to exhaustion $(\tau \pm 20)$. By ocular inspection, also this suggests a cutoff at $T=40$ being reasonable. Below 40 remaining years, there are many observations which exhibit a rather high price growth whereas, for the observations with more remaining years, price growth is more centered around zero. ${ }^{46}$

\subsection{Sensitivity analysis for 40 years rolling horizon model of the oil market}

Firstly, varying the extraction cost parameters of $\theta$ and $g_{m}$ does not alter the model results to any considerable extent as long as $\theta$ remains between 0.7 and 1.3 and the technological improvement in mining is kept between zero and three percent annually. Depending on the exact values, we may get a price which is closer to constant in the earlier years and a slight change of the slope after 1998. Thus, it seems that the extraction costs are roughly linear on the aggregate level in the long run and that mining technology has improved

\footnotetext{
${ }^{45}$ Another important note is that given the repeated regression procedure the standard errors should, strictly speaking, be corrected. Doing this would make all results insignificant, i.e. both the infinite and rolling horizon models could not be supported. However, it is not obvious how such a correction should be formalized. The reason is that the significant results do not show up at arbitrary cutoffs or in only one regression. Rather, there is a clear pattern whereby $a_{2}$ attains its largest value, the p-value is the smallest and the residual is minimized at the regressions where $\tau$ is around 40. As we move away from this time horizon $a_{2}$ falls rather monotonically and p-values and residuals increase monotonically which follows the predictions of the rolling horizon model. So, we have a convex set of cutoffs with significant results making the multiple regression results internally consistent. Saying that each one of these regression results is insignificant would then suggest that we cannot support any of the models when in fact the results point at an empirical regularity. Namely, that those observations with few years left to exhaustion seem to behave differently than those with many years left and that this difference seems to increase towards $T=40$ and decrease afterwards in a rather monotonic fashion.

${ }^{46}$ Although it is not entirely clear whether this comes just from higher variance of the observations.
} 

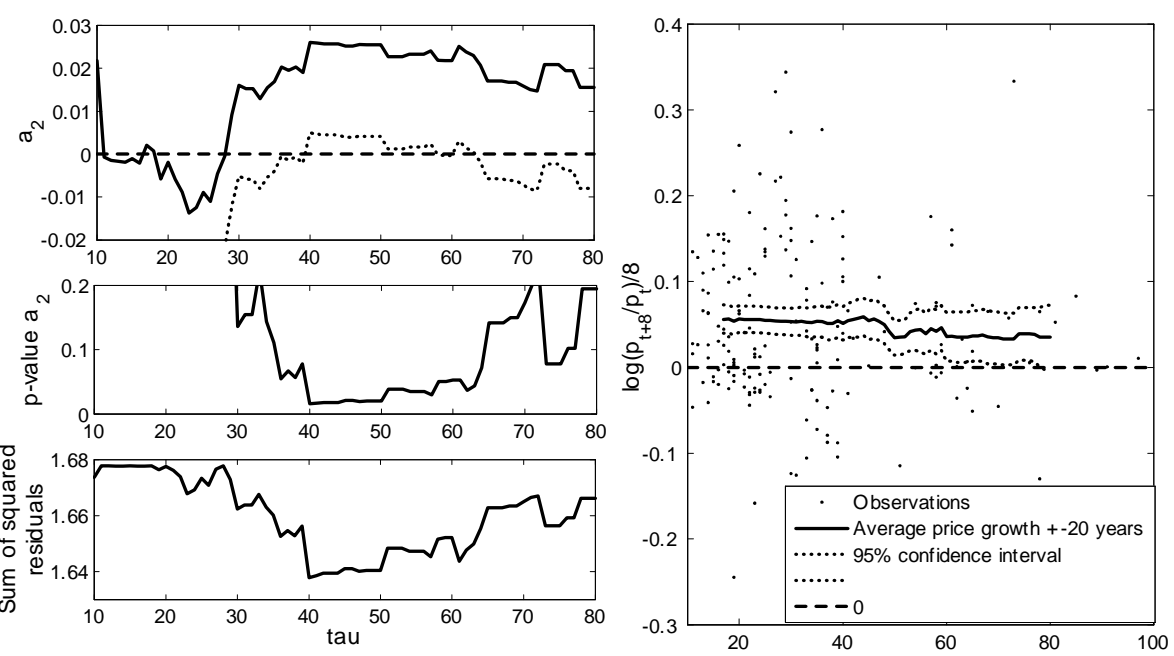

Figure 8: Results of multiple regressions of equation (18). Observation include those with reserve revisions of $0-10 \%$.

at a low to medium rate. ${ }^{47}$ If, instead, we change the average production cost to be below $12 \$$ in 2008 , the main effect is to shift the price schedule uniformly downwards while the broad shape of first slowly decreasing prices and then sharply increasing prices around 1998 remains. Finally, it makes little difference if we assume that the beliefs of the stocks in each year is what was reported in that year. The reason for this is that, in the simulation, only during few of the years prior to 2000 the resource constraint is binding within 40 years. Hence, the resource owner's behavior up until the switch of phases just before the year 2000 is intact under this alternative assumption.

\footnotetext{
${ }^{47}$ Implicitly, when matched with data, the parameter $g_{m}$ also catches the possibility that extraction costs may go up as extraction is performed at more costly locations or due to falling well-pressure.
} 


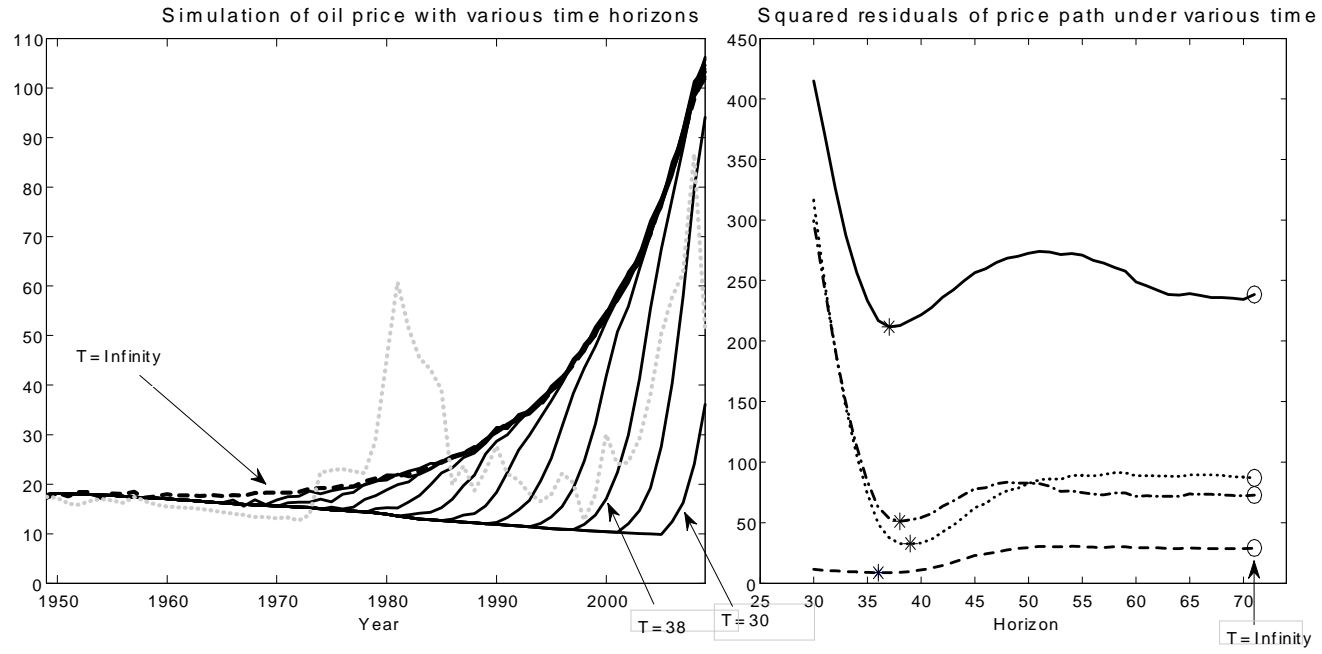

Figure 9: Left: Model oil price with various horizons lengths $(T=30 \ldots 70$ and $T=\infty)$ and data (grey dotted). Right: Squared residuals under each horizon. All years without level compensation (dashed); All years with level compensation (solid); Excluding "oilcrisis" years with level compensation (dashed-dotted); Interpolating over "oil-crisis" years with level compensation (dotted); Residuals for infinite horizon (circles); MLE for each residual (stars). 